\title{
Proton Sensing on the Ocular Surface: Implications in Eye Pain
}

\author{
Núria Comes ${ }^{1,2}$, Xavier Gasull ${ }^{1,2}$ and Gerard Callejo ${ }^{1,2 *}$ \\ ${ }^{1}$ Neurophysiology Laboratory, Department of Biomedicine, Medical School, Institute of Neurosciences, Universitat de Barcelona, \\ Barcelona, Spain, ${ }^{2}$ Institut d'Investigacions Biomèdiques August Pi i Sunyer (IDIBAPS), Barcelona, Spain
}

Protons reaching the eyeball from exogenous acidic substances or released from damaged cells during inflammation, immune cells, after tissue injury or during chronic ophthalmic conditions, activate or modulate ion channels present in sensory nerve fibers that innervate the ocular anterior surface. Their identification as well as their role during disease is critical for the understanding of sensory ocular pathophysiology. They are likely to mediate some of the discomfort sensations accompanying several ophthalmic formulations and may represent novel targets for the development of new therapeutics for ocular pathologies. Among the ion channels expressed in trigeminal nociceptors innervating the anterior surface of the eye (cornea and conjunctiva) and annex ocular structures (eyelids), members of the TRP and ASIC families play a critical role in ocular acidic pain. Low pH (pH 6) activates TRPV1, a polymodal ion channel also activated by heat, capsaicin and hyperosmolar conditions. ASIC1, ASIC3 and heteromeric ASIC1/

OPEN ACCESS

Edited by:

Dario Rusciano,

Sooft Italia SpA, Italy

Reviewed by:

Ernest Jennings,

James Cook University, Australia

Philippe Séguéla,

McGill University, Canada

${ }^{*}$ Correspondence:

Gerard Callejo

gerard.callejo@ub.edu

Specialty section: This article was submitted to

Neuropharmacology,

a section of the journal

Frontiers in Pharmacology

Received: 10 September 2021

Accepted: 09 November 2021

Published: 24 November 2021

Citation:

Comes NA, Gasull $X$ and Callejo $G$ (2021) Proton Sensing on the Ocular

Surface: Implications in Eye Pain.

Front. Pharmacol. 12:773871.

doi: 10.3389/fphar.2021.773871
ASIC3 channels present in ocular nerve terminals are activated at $\mathrm{pH} 7.2-6.5$, inducing pain by moderate acidifications of the ocular surface. These channels, together with TRPA1, are involved in acute ocular pain, as well as in painful sensations during allergic keratoconjunctivitis or other ophthalmic conditions, as blocking or reducing channel expression ameliorates ocular pain. TRPV1, TRPA1 and other ion channels are also present in corneal and conjunctival cells, promoting inflammation of the ocular surface after injury. In addition to the above-mentioned ion channels, members of the $\mathrm{K}_{2 \mathrm{P}}$ and P2X ion channel families are also expressed in trigeminal neurons, however, their role in ocular pain remains unclear to date. In this report, these and other ion channels and receptors involved in acid sensing during ocular pathologies and pain are reviewed.

Keywords: ocular surface, pain, ion channels, protons, ocular disease

\section{INTRODUCTION}

Physical and chemical stimuli from the environment are sensed by sensory nerve terminals present in the cornea and conjunctiva. Whereas the cornea lies in front of the iris and pupil, the conjunctiva covers the posterior part of the eyelids (palpebral conjunctiva) towards the conjunctival fornix and continues with the anterior part of the sclera until the corneoscleral limbus (bulbar conjunctiva). Both structures are the first line of defense against potential damaging stimuli of the inner eye structures and are covered by a tear film that moistures and lubricates the anterior ocular surface avoiding damage of the corneal epithelium. Acidic insults can reach the ocular surface when we are in contact with exogenous acidic substances. Besides, different infections, allergic or inflammatory conditions can promote an acidic environment in the cornea or the conjunctiva. Moreover, many 


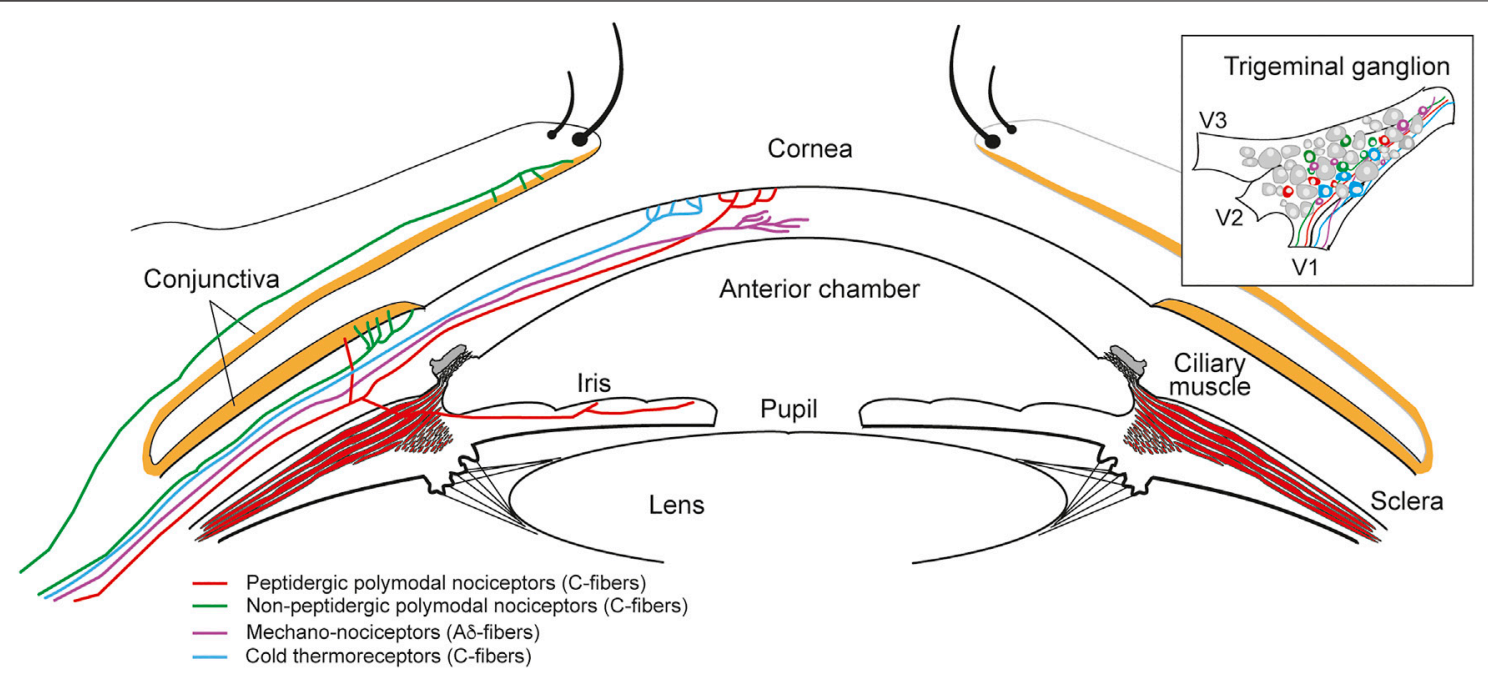

FIGURE 1 | Sensory innervation of the ocular anterior segment. Diagram of the anterior part of the eye showing the different types of nerve fibers innervating the different structures and the ocular surface. Sensory innervation is provided by the ophthalmic nerve arising from the $\mathrm{V} 1$ branch of the trigeminal ganglion (upper right inset).

ophthalmic drugs used as eyedrops are formulated in acidic solutions to be able to solubilize or stabilize the active compound. All these acidic stimuli activate different mechanisms in the ocular surface, mostly ion channels activated by protons in peripheral sensory nerves, which detect and transduce these stimuli to higher brain areas to evoke painful sensations and to induce protective responses. Acidic conditions can also activate ion channels in corneal epithelial, endothelial or conjunctival cells, thus promoting inflammatory states. The mechanisms involved in proton sensing in these ocular structures are reviewed in this report.

\section{THE OCULAR SURFACE}

\subsection{Ocular Innervation}

The trigeminal ganglion, through the ophthalmic nerve, provides non-visual sensory innervation to the entire eyeball. Peripheral axons of trigeminal neurons innervate the anterior ocular surface, namely the cornea and conjunctiva, but also the uvea (Figure 1), where they have a critical role in ocular inflammation (Mintenig et al., 1995; Belmonte et al., 1997). Most of the sensory neurons innervating the eye detect mechanical, thermal and chemical stimuli in the noxious range to protect the eyeball, evoking responses to minimize damage and to promote tissue repair. Besides, Edinger-Westphal nucleus localized in the brainstem supplies autonomic parasympathetic innervation of the eye through the oculomotor nerve (ten Tusscher et al., 1994; Reiner et al., 1983). The iris, the ciliary body/ciliary muscle and parts of the iridocorneal angle (uveal trabecular meshwork and scleral spur) are innervated by parasympathetic nerve fibers that synapse in the ciliary ganglion, entering the ocular globe through the short ciliary nerves. In addition, some parasympathetic fibers arrive from the pons through the geniculate ganglion (Petrosal). Later, they synapse in the pterygopalatine ganglion before entering the eye (Ruskell, 1970). Furthermore, sympathetic nerve fibers from the superior cervical ganglion innervate the eyeball through both the long and short ciliary nerves. They innervate the ciliary body (central stroma and stroma of the ciliary processes), the iris and parts of the iridocorneal angle (Figure 1). Contrary, the cornea is innervated almost exclusively by sensory fibers, lacking autonomic innervation.

As mentioned, the ocular surface is densely innervated by trigeminal sensory neurons (Belmonte et al., 2004; Belmonte et al., 2011; Belmonte, 2019), most of them nociceptors (pain sensory neurons; Figure 1). Two main types of nociceptors are present: about $70 \%$ are polymodal nociceptors (C-fibers) that respond to mechanical stimulation, extreme temperatures, exogenous chemical irritants and endogenous molecules released by tissue injury. Between 15 and $20 \%$ of the nerve fibers are mechano-nociceptors (A $\delta$-fibers), activated by noxious mechanical forces. Finally, cold thermoreceptors constitute the third population of fibers that innervate the cornea $(10-15 \%)$, which detect changes in temperature in the non-noxious cold range and regulate basal tearing rate among other functions (Belmonte et al., 2004; Belmonte, 2019). Several ion channels present in the peripheral terminals of these neurons have been characterized and play significant roles in ocular pain (acute, inflammatory or of neuropathic origin), including the sensitivity to protons, as well as in other ocular sensations, such as ocular dryness (Figure 2). A description of some of these ion channels and receptors is detailed in the following sections.

Recent studies using next-generation sequencing techniques have defined 11 subtypes of Dorsal Root Ganglia (DRG) sensory neurons according to different membrane receptors, ion channels, transcription factors and neuropeptides characteristically and similarly expressed (Chiu et al., 2014; 

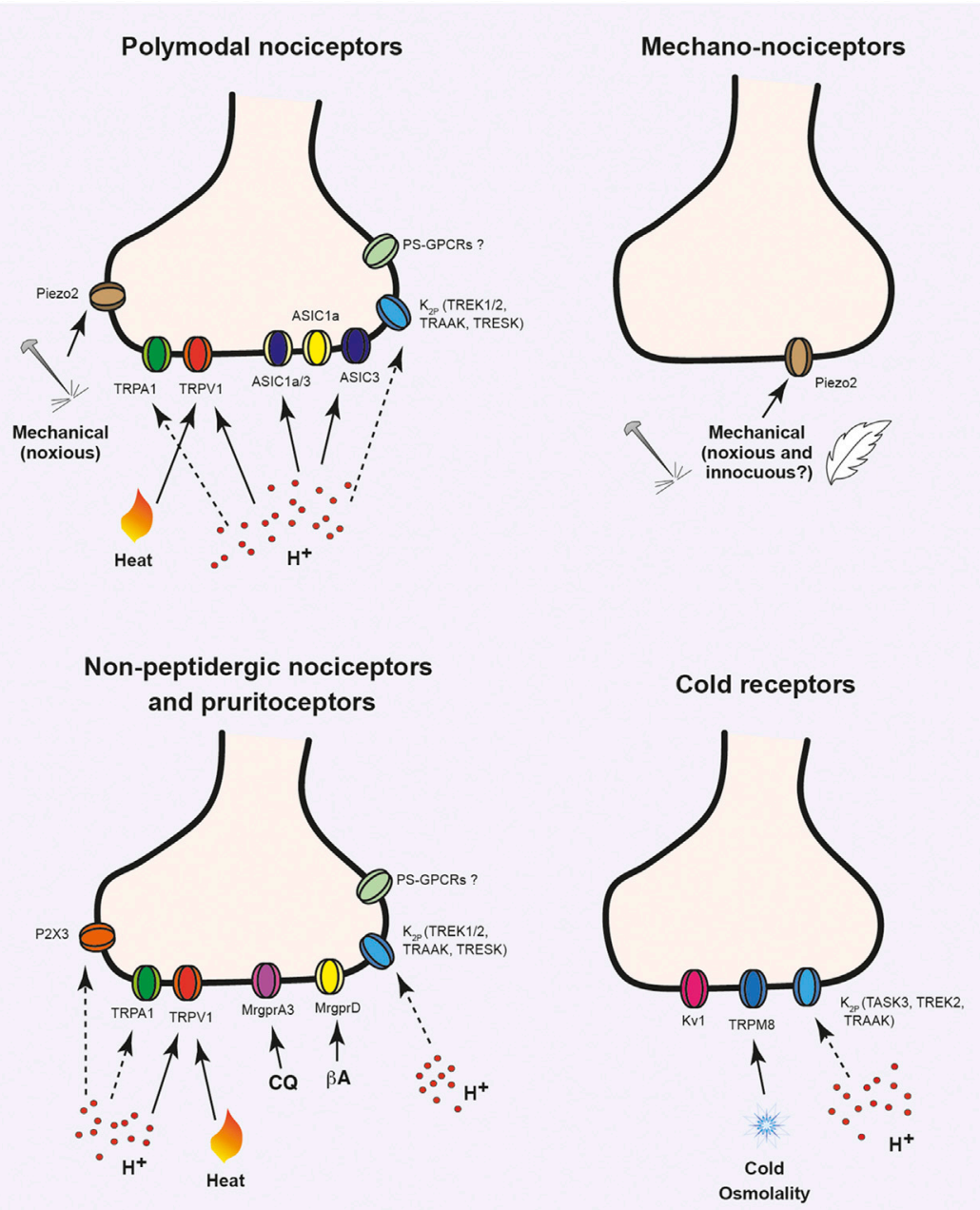

FIGURE 2 | lon channels activated or modulated by acidic stimuli in ocular sensory neurons. Ion channels expressed in trigeminal sensory neuron terminals innervating the cornea, sclera and conjunctiva. Different types of nociceptive fibers are shown: mechano-nociceptors that respond to high threshold mechanical stimulation; polymodal nociceptors, which can be activated by chemical, mechanical and thermal (noxious heat or cold) stimulation; cold thermoreceptors that express TRPM8 and respond to non-noxious cold stimuli and non-peptidergic sensory neurons, involved in nociception and itch sensitivity. Solid lines indicate direct activation by stimulus. Dashed lines indicate modulation of ion channel activity by protons. CQ, chloroquine; $\beta \mathrm{A}, \beta$-alanine.

Usoskin et al., 2015; Zeisel et al., 2018). The classification of these neurons according to their gene expression patterns and the known roles of these genes on sensory transduction and neuronal excitability, has permitted to define different subgroups of neurons according to their putative function. Therefore, we can differentiate populations of low-threshold mechanoreceptors (touch) and proprioceptors, cold thermoreceptors, heat thermoreceptors as well as peptidergic and non-peptidergic nociceptors activated by high threshold mechanical, thermal or chemical stimuli (Usoskin et al., 2015; Nguyen et al., 2017; Zeisel et al., 2018). Also, specific subpopulations of nociceptors have been described to respond specifically to pruritogens and can be classified as itch receptors or pruritoceptors.

Despite most of the studies have been done in DRG neurons, a few transcriptomic studies in the whole trigeminal ganglia have been done (Flegel et al., 2015; Nguyen et al., 2017; LaPaglia et al.,
2018). Trigeminal neurons show a similar distribution of sensory neuron subtypes according to their gene subpopulation markers, which, in general, are similar to those found in the DRG, but specific differences in gene expression are present (Flegel et al., 2015; Nguyen et al., 2017; LaPaglia et al., 2018). A specific transcriptomic study on ocular sensory neurons is still lacking but evidence from different transgenic animal models or from functional studies indicate that some of these neuronal subpopulations of neurons identified in the DRGs or in the TGs neurons specifically innervate different parts of the ocular surface. Specifically, the larger population of sensory neurons innervating the cornea are peptidergic polymodal nociceptors (for review see Belmonte et al. (2011), Belmonte (2019)). At the transcriptomic level, these neurons express distinctive nociceptive markers such as the capsaicin and heat sensitive ion channel TRPV1 (Transient Receptor Potential cation channel subfamily $\mathrm{V}$ member 1 ), the ion channel TRPA1 
(Transient Receptor Potential cation channel subfamily A member 1) activated by irritant substances as well as the neuropeptides calcitonin gene-related peptide (CGRP) and substance P (Nguyen et al., 2017). Functional studies have shown that corneal neurons respond to acid, hot temperatures, mechanical stimuli and capsaicin (Chen et al., 1997; López de Armentia et al., 2000; Cabanes et al., 2002; González-González et al., 2017), which is in agreement with their receptor's expression. Thus, upon stimulation, peripheral terminals of sensory neurons release CGRP and substance $\mathrm{P}$, which are proinflammatory neuropeptides and contribute to neurogenic inflammation and nociceptor sensitization. Although it has not been clearly demonstrated, it is possible that a population of $\mathrm{A} \delta$ fibers constituting "silent" nociceptors innervates the cornea and annex ocular structures. It is thought that these sensory terminals are only activated after local inflammation occurs and the fibers are somehow sensitized. The cellular correlate of these fibers has not been yet established.

Besides polymodal nociceptors, mechanonociceptor neurons (15-20\%) only respond to high threshold mechanical stimuli and they express the mechanosensitive channel Piezo2 but do not express neuropeptides (e.g., CGRP) or the cold-sensitive ion channel TRPM8 (Transient Receptor Potential cation channel subfamily $M$ member 8), thus constituting a different subpopulation of corneal neurons besides polymodal nociceptors or cold thermoreceptors (Bron et al., 2014). The last population of sensory neurons innervating the cornea are cold thermoreceptors that express TRPM8. They provide profound innervation of the corneal epithelium and respond to moderate cold stimuli and to changes in osmolarity (Parra et al., 2010; Parra et al., 2014; Quallo et al., 2015). Importantly, these neurons are activated in ocular dryness conditions, when temperature slightly decreases and osmolarity increases due to tear evaporation. Their increase in firing activates a brainstem neuronal loop that regulates basal tearing and blinking rate (Parra et al., 2010; Parra et al., 2014; Quallo et al., 2015). At the molecular and functional levels two populations of TRPM8 have been identified. One presents a high expression pattern of TRPM8 and a lower threshold for activation by cold (González-González et al., 2017; Nguyen et al., 2017), whereas the second one shows a lower expression of TRMP8 and a higher threshold for activation (activation at lower temperatures). This population might coexpress other channels like TRPV1 and could be functionally similar to polymodal nociceptors (González-González et al., 2017).

Interestingly, the conjunctiva, presents a different pattern of innervation compared with the cornea. Two neuronal populations innervate this structure but not the cornea: nonpeptidergic MAS-related G protein-coupled receptor member D positive neurons $\left(\mathrm{MrgprD}^{+}\right)$and $\mathrm{MrgprA3}^{+}$sensory neurons (Huang et al., 2018). MrgprD ${ }^{+}$neurons also express lysophosphatidic acid receptors LPAR3 and LPAR5 and are involved in mechanical pain and skin itch mediated by $\beta$-alanine. In the eye, $\operatorname{MrgprD}^{+}$fibers mainly innervate the marginal conjunctiva, a region that contacts with the eye surface during blinking (lid wiper) (Huang et al., 2018). Conversely, MrgprA3 ${ }^{+}$fibers are enriched in medial and lateral conjunctival areas (corners of the eye). These fibers are also activated by histamine, serotonin, chloroquine (an MrgprA3 agonist) and NPFF (that activates MrgprC11), constituting a common pathway for ocular itch (Huang et al., 2016; Huang et al., 2018).

\subsection{Ion Channels in Ocular Sensory Neurons}

The different types of sensory neurons innervating the ocular surface express multitude of ion channels that detect and transduce different physical, thermal or chemical stimuli or that participate in the electrical activity of these neurons (Figure 2). As mentioned earlier, different members of the Transient Receptor Potential (TRP) family of ion channels are present ocular sensory neurons. Particularly, cold thermoreceptors express TRPM8, activated by moderate cold stimuli and menthol (Belmonte and Gallar, 2011). Polymodal nociceptors express TRPV1 and TRPA1 (Belmonte et al., 1991; González-González et al., 2017), purinergic P2X receptors as well as members of the Acid-Sensing Ion Channels, since ASIC1 and ASIC3 currents have been detected in corneal sensory neurons (Callejo et al., 2015). The mechanotransducer channel Piezo2 is present in about $30 \%$ of corneal afferent neurons (Bron et al., 2014). Although some expression might exist in some polymodal nociceptors, Piezo2 seems to be mostly restricted to medium- to large-sized sensory neurons positive for neurofilament 200 (NF200) and negative for TRPV1 and CGRP, which suggests its expression in pure mechanonociceptors conducting in the range of $A \delta$-fibers rather than corneal polymodal nociceptors (Bron et al., 2014; Fernández-Trillo et al., 2020). Moreover, sensory-specific ablation of Piezo2 reduces the percentage of corneal mechanosensitive neurons in vitro (Fernández-Trillo et al., 2020). Conjunctival MrgprD ${ }^{+}$and MrgprA3 $^{+}$afferent neurons also contain TRPV1 and TRPA1 channels that participate in itch stimuli transduction (Huang et al., 2016). These neuronal subpopulations also present a characteristic expression of different ion channels involved in the generation and propagation of action potentials (APs) and in the control of neuronal excitability such as voltage-gated sodium $\left(\mathrm{Na}_{\mathrm{v}} 1.7,1.8\right.$, and 1.9), calcium (Cacna1/2/3), potassium (Kcns1, Kcnip4) channels and members of the $\mathrm{K}_{2 \mathrm{P}}$ ion channel family.

Several of these channels are directly activated by protons or modulated by them, thus constituting the transducers for acidic stimuli in the ocular surface (Figure 2). A detailed role of each channel is provided below.

\section{PROTON-SENSING IN THE OCULAR SURFACE}

\subsection{TRPV1}

The vanilloid receptor TRPV1 is one of the best characterized members of the subfamily of the thermosensitive channels TRP. It is a non-selective cation channel permeable to $\mathrm{Na}^{+}$and $\mathrm{Ca}^{2+}$ and its activation depolarizes nociceptive sensory neurons (Basbaum et al., 2009). In fact, it has been mainly detected in nociceptors of the trigeminal and the dorsal root ganglia (Clapham, 2003) although they have been found in different 
brain regions (Tóth et al., 2005). As mentioned before, TRPV1 is a molecular transducer of thermal and chemical painful stimuli, playing a significant role in nociception (Caterina et al., 1997). It is activated by noxious heat, with a thermal threshold activation of $>42^{\circ} \mathrm{C}$, low $\mathrm{pH}$, voltage and capsaicin, the pungent component responsible for the spiciness of chili peppers (Caterina et al., 1997; Tominaga et al., 1998). TRPV1-mediated thermal sensitivity can be modulated by a variety of components of the inflammatory soup (Tominaga et al., 1998; Pethö and Reeh, 2012). Thus, a variety of endogenous bioactive lipids act as positive allosteric regulators of TRPV1 while proinflammatory agents such as cytokines, prostaglandins, bradykinin and neurotrophins act on their specific receptors modulating TRPV1 through intracellular signaling pathways. TRPV1 activity is essential in the cellular mechanisms by which tissue damage and nociceptor persistent activation can cause acute sensitivity to noxious heat stimuli, thermal hyperalgesia and neurogenic inflammation (Caterina et al., 2000; Szolcsányi and Sándor, 2012). TRPV1 is widely used as a molecular marker for a specific subset of polymodal nociceptors, the small-diameter peptidergic C-fibers characterized by being unmyelinated, slow-conducting and, in most cases, expressing substance P and CGRP (Tominaga et al., 1998).

As mentioned in the previous section, in mammals, the cornea is mainly innervated by three types of afferent sensory neurons: polymodal nociceptors, mechano-nociceptors and cold-sensitive neurons. In this regard, the presence of TRPV1 in the cornea was initially identified in heat-sensitive polymodal nociceptors by topical application of hypertonic saline, acetic acid and capsaicin (Belmonte and Giraldez, 1981; Belmonte et al., 1988; Belmonte et al., 1991; Gallar et al., 1993). Specifically, about 50\% of corneal polymodal C-fibers are stimulated by capsaicin in cats (Belmonte et al., 1991; Chen et al., 1997). Subsequently, TRPV1 channel has been detected almost exclusively in small-diameter $\mathrm{C}$ axons colocalizing with CGRP and SCGII (secretogranin II) (Kobayashi et al., 2005; Schecterson et al., 2020).

After reporting the dense innervation of the cornea by the ophthalmic branch of the trigeminal nerve (Arvidson, 1977), the molecular profile of corneal trigeminal neurons expressing TRPV1 has been determined by neuronal retrograde tracing. An important percentage of corneal afferent nerve fibers express TRPV1 in different tested animals (González-González et al., 2017). In guinea pig, $45 \%$ of corneal sensory fibers are positive for TRPV1 (the molecular marker of polymodal nociceptors), 28\% are positive for Piezo2 (the putative marker of mechanonociceptors) whereas $8 \%$ of them express TRPM8 (a marker of cold-sensitive neurons). In addition, no co-expression between TRPV1 and Piezo 2 has been detected in this class of nerve fibers but $6 \%$ of TRPV1-immunoreactive neurons also expressed TRPM8. The same study has reported that more than $90 \%$ of TRPV $1^{+}$corneal afferents are probably polymodal nociceptors (Alamri et al., 2015). In rat trigeminal ganglion, 37\% of corneal afferent sensory neurons has been found to express TRPV1 while around one third of the TRPV $1^{+}$afferents express substance $\mathrm{P}$ and three quarters of these co-expressed CGRP. Therefore, TRPV1 could act in conjunction with substance $\mathrm{P}$ and/or CGRP to transduce nociception in corneal sensory neurons
(Murata and Masuko, 2006). In contrast, a slightly lower proportion $(23 \%)$ of rat corneal afferents has been reported to express TRPV1 in another study (Nakamura et al., 2007). In addition to the different animal models used in the studies, this variability in the proportion of sensory neurons expressing TRPV1 could be explained because cholera toxin subunit B, used in most of the mentioned studies, preferentially labels neurons with large cell bodies whereas the retrograde tracer Fluorogold used in the study led by Nakamura is known to label small and large neurons. In addition to neuronal retrograde tracing, immunohistochemistry and double label in situ hybridization, the presence of TRPV1 in corneal polymodal nociceptors has been functionally demonstrated with the strong tearing and blinking response evoked by ocular application of capsaicin (Gonzalez et al., 1993; GonzálezGonzález et al., 2017).

The functional effect of capsaicin on TRPV1 in sensory nerve fibers and its capacity to elicit a burning sensation in the eye allowed to suggest that the action of capsaicin could be involved in the perception of painful thermal stimuli in vivo (Caterina et al., 1997). Besides, protons can positively modulate the activation of capsaicin-sensitive sensory neurons, enhancing the capsaicin effect (Petersen and LaMotte, 1993). Experimentally, the stimulation of corneal polymodal nociceptors by extracellular protons can be achieved by the application of acidic solution (such as acid acetic solutions) (Chen et al., 1995) or by pulses of a gas mixture with $\mathrm{CO}_{2}$ applied to the corneal surface (Belmonte et al., 1999). In the latter case, $\mathrm{CO}_{2}$ combines with $\mathrm{H}_{2} \mathrm{O}$ in the tear film covering the cornea resulting in carbonic acid formation which effectively decreases the $\mathrm{pH}$ despite the buffering capacity of bicarbonate-containing tears. In parallel, corneal pain has been quantified in humans as a response to the same stimuli with $\mathrm{CO}_{2}$ demonstrating that activation of nociceptors expressing TRPV1 by acidic $\mathrm{pH}$ could be a cause of pain following tissue injury (Chen et al., 1995). Human subjects identify burning pain and irritation sensation experimentally caused by acidic stimulation $\left(\mathrm{CO}_{2}\right.$ pulses) on the corneal surface, that it is known to recruit polymodal sensory afferents in the cat's cornea (Acosta et al., 2001a).

Interestingly, TRPV1 can be a target to manage pain perception and it could be useful after an injury or at postoperative level (Weyer-Menkhoff and Lötsch, 2018). Resiniferatoxin (RTX), a potent TRPV1 agonist, strongly activates TRPV1 generating cellular toxicity resulting from an excessive influx of calcium (Olah et al., 2001). When RTX is administered peripherally, it produces reversible analgesia due to the inactivation of nociceptors expressing TRPV1 (Neubert et al., 2003). Subsequent studies have shown that RTX directly infused into the trigeminal ganglion eliminates pain perception as well as neurogenic inflammation. In the rat cornea, a single topical application of RTX reduces capsaicin sensitivity producing transient analgesia for up to 5 days with no adverse side effects observed in histological studies (Table 1; Bates et al., 2010). Therefore, RTX could have the potential to manage acute pain caused by ophthalmic surgeries, and corneal conditions such as abrasions or ulcers. For chronic pain, it remains to be 
TABLE 1 | Proton-sensing ion channels involved in ocular surface pathologies.

\begin{tabular}{|c|c|c|c|c|c|c|}
\hline Channel & Disease & Treatment & Effects & Behavioral response & $\begin{array}{l}\text { Animal } \\
\text { model }\end{array}$ & References \\
\hline \multirow[t]{5}{*}{ TRPV1 } & Ocular pain & $\begin{array}{l}\text { Resiniferatoxin } \\
\text { (RTX, agonist) }\end{array}$ & $\mathrm{Ca}^{2+}$-induced cytotoxicity & $\begin{array}{l}\text { Reduces capsaicin-induced eye } \\
\text { wiping }\end{array}$ & Rat & Neubert et al. (2003) \\
\hline & $\begin{array}{l}\text { Allergic } \\
\text { keratoconjuntivitis }\end{array}$ & $\begin{array}{l}\text { Capsazepine } \\
\text { (antagonist) }\end{array}$ & $\begin{array}{l}\text { Abolishes nerve fiber } \\
\text { spontaneous activity; reduces } \\
\text { firing response }\end{array}$ & Attenuates eye blinking and tearing & $\begin{array}{l}\text { Guinea } \\
\text { pig }\end{array}$ & Bates et al. (2010) \\
\hline & Dry eye disease & $\begin{array}{l}\text { siRNA Tivanisiran } \\
\text { (SYL1001) }\end{array}$ & Not tested & $\begin{array}{l}\text { Improves tear quality and } \\
\text { hyperemia; reliefs ocular } \\
\text { discomfort and pain, avoid damage } \\
\text { to the ocular surface }\end{array}$ & Rat & $\begin{array}{l}\text { Moreno-Montañés et al. } \\
\text { (2018), Fakih et al. (2021) }\end{array}$ \\
\hline & Dry eye disease & $\begin{array}{l}\text { A784168 } \\
\text { (antagonist) }\end{array}$ & Not tested & $\begin{array}{l}\text { Reduces increased eye blinking } \\
\text { induced by lacrimal gland excision }\end{array}$ & $\begin{array}{l}\text { Guinea } \\
\text { pig }\end{array}$ & $\begin{array}{l}\text { Benitez-Del-Castillo et al. } \\
\text { (2016) }\end{array}$ \\
\hline & Photokeratitis & $\begin{array}{l}\text { Capsaicin } \\
\text { (agonist) }\end{array}$ & Not tested & Increased blinking & $\begin{array}{l}\text { Guinea } \\
\text { pig }\end{array}$ & Acosta et al. (2013) \\
\hline \multirow[t]{2}{*}{ TRPA1 } & $\begin{array}{l}\text { Allergic } \\
\text { keratoconjuntivitis }\end{array}$ & $\begin{array}{l}\text { HC-030031 } \\
\text { (antagonist) }\end{array}$ & $\begin{array}{l}\text { Reduces mechanical threshold; } \\
\text { attenuates responsiveness } \\
\text { to } \mathrm{CO}_{2}\end{array}$ & Attenuates eye blinking & $\begin{array}{l}\text { Guinea } \\
\text { pig }\end{array}$ & Bates et al. (2010) \\
\hline & $\begin{array}{l}\text { Corneal injury and } \\
\text { inflammation }\end{array}$ & $\begin{array}{l}\text { TRPA1 }{ }^{-/-} \\
\text {Knockout mice }\end{array}$ & $\begin{array}{l}\text { Decrease macrophage } \\
\text { infiltration; stromal } \\
\text { neovascularization and fibrosis }\end{array}$ & Not tested & Mouse & Katagiri et al. (2015) \\
\hline \multirow[t]{2}{*}{ ASIC3 } & $\begin{array}{l}\text { Allergic } \\
\text { keratoconjuntivitis }\end{array}$ & $\begin{array}{l}\text { APETx2 toxin } \\
\text { (antagonist) }\end{array}$ & Not tested & Reduces allergen-induced blinking & Rat & Callejo et al. (2015) \\
\hline & Dry eye disease & $\begin{array}{l}\text { APETx2 toxin } \\
\text { (antagonist) }\end{array}$ & Not tested & No effect on acid-induced blinking & Rat & Callejo et al. (2015) \\
\hline
\end{tabular}

determined whether reapplication of RTX generate longer lasting corneal analgesia. Likewise, treatment with the TRPV1 antagonist capsazepine, prior to allergic challenge, abolishes spontaneous activity and sensitivity to heat of polymodal nociceptors and reduces their firing response to a $\mathrm{CO}_{2}$-mediated acidic stimulus (Table 1). It also attenuates the increased blinking rate found in a model for allergic keratoconjunctivitis in guinea pig (Acosta et al., 2013). Because the augmented blinking is considered a nocifensive response to the eye discomfort caused by the high chemical activation of polymodal nociceptors, TRPV1 has been associated to ocular irritation during allergic episodes (Acosta et al., 2013). In a similar way, an increased blinking rate to topical capsaicin has been described in a guinea pig model of keratitis performed by eye exposure to UV radiation (photokeratitis; Table 1). Hence, the discomfort sensation reported by humans after UV irradiation may be the result of sensitization of polymodal nociceptors by the local release of inflammatory mediators and TRPV1 activation (Acosta et al., 2014). In addition to allergic keratoconjunctivitis and photokeratitis, polymodal nociceptors may play a role in other pathologies that affect the cornea like herpes simplex virus keratitis (Gallar et al., 2010) and corneal sensitivity associated to diabetes mellitus (Neira-Zalentein et al., 2011).

A significant number of TRPM8-expressing sensory neurons also express TRPV1 and this channel could be involved in cold nociception of the cornea enhancing excitability of TRPM $8^{+}$cells (Li et al., 2019). TRPV1 could also act as a pharmacological target for the treatment of dry eye disease (DED), characterized by tear instability, ocular dryness, irritation, itch, pain and visual disturbances, and commonly linked with ocular surface inflammation (Messmer, 2015). Co-expression between TRPV1 and TRPM8 channels is increased in corneal cool cells of the experimental rat model for DED performed by lacrimal gland excision (LGE), that shows enhanced sensitivity to capsaicin (Hatta et al., 2019). Besides, different studies propose that TRPV1 could intervene in the increased nocifensive response associated with DED in rats treated with the LGE procedure (Bereiter et al., 2018). In this sense, mRNA expression of TRPV1, TRPA1, ASIC1, and ASIC3 is upregulated in the ophthalmic division of the trigeminal ganglion of a mice model of chronic DED (Fakih et al., 2021). Interestingly, instillation of capsazepine not only inhibits the aforementioned genetic upregulation but also reliefs corneal neurosensory symptoms and reduces anxietylinked behaviors that characterize severe DED. Similarly, TRPV1 protein levels have been found increased in the trigeminal ganglion of a rat model of $\mathrm{DED}$, in which the channel is involved in the enhanced nocifensive responses (Bereiter et al., 2018). Taken together, TRPV1 antagonists could be potential analgesics for DED treatment (Fakih et al., 2021). Likewise, topical administration of tivanisiran (formerly named SYL1001), a siRNA designed to silence the expression of TRPV1, improves tear quality, hyperemia, ocular pain and discomfort characteristic of DED (Moreno-Montañés et al., 2018). Thus, Phase I and II clinical trials have already determined the most effective doses for its therapeutic use to alleviate DED symptoms (Benitez-Del-Castillo et al., 2016). In the same sense, topical application of A784168, a potent antagonist of TRPV1, diminishes the blink rate in a model of chronic tear deficiency in guinea pig (Masuoka et al., 2020).

\subsection{TRPA1}

TRPA1, the only member of the subfamily of ankyrin TRP channels described, is a voltage-dependent, non-selective channel permeable to $\mathrm{Ca}^{2+}, \mathrm{Na}^{+}$, and $\mathrm{K}^{+}$. TRPA1 is expressed 
in sensory neurons that innervate skin, intestinal and pulmonary epithelium, inner ear hair cells and olfactory epithelium, among others (Basbaum et al., 2009). It has a similar main structure as TRPV1 with some specific features such as the presence of a longterminal ankyrin domain including the regions that confer the thermal and chemical sensitivity (Cordero-Morales et al., 2011) and a TRP-like domain after the S6 transmembrane segment instead of the standard TRP motif. TRPA1 channel contributes to the perception of a great variety of chemical substances that causes pain manifested as burning, skin and eye irritation as well as thermal and mechanical hypersensitivity (Bandell et al., 2004). Reactive chemicals that activate TRPA1 include allyl isothiocyanate (AITC) (the pungent compound found in horseradish, mustard oil and wasabi), cinnamaldehyde (the organic compound responsible for the characteristic taste and smell of cinnamon), allicin (from garlic extract) and diallyl disulfide (from onion) (Logashina et al., 2019). TRPA1 is also activated in response to noxious cold temperatures $\left(<17^{\circ} \mathrm{C}\right)$ and endogenous agents such as reactive oxygen species (Logashina et al., 2019). Moreover, it senses environmental irritants such as tear gas, acrolein from air pollution and tobacco smoke and endogenous proalgesic and proinflammatory agents (Bautista et al., 2006; Lindsay et al., 2014). In addition, TRPA1-deficient mice show a significant reduction in painful responses to formaldehyde and 4-hydroxynonenal, which are aldehydes that activate TRPA1 (Macpherson et al., 2007). Furthermore, TRPA1 has been associated to chronic itch (Wilson et al., 2013) and hypersensitivity in different experimental models of persistent inflammatory pain (Dai et al., 2007; Lennertz et al., 2012). Thus, TRPA1 could have a great potential as analgesic and antiinflammatory target to treat pathologies such as different types of dermatitis (Liu et al., 2013; Oh et al., 2013) and migraine (Materazzi et al., 2013).

TRPA1 is expressed in approximately $35 \%$ of the sensory neurons of the trigeminal ganglion (Jordt et al., 2004). In the mouse cornea, TRPA1 channel is mainly expressed in mediumdiameter myelinated A $\delta$-fibers where it colocalizes with neurofilament protein NF200 and secretogranin 3 (SCG3) although it is also present in C-fiber nociceptive sensory neurons (Figure 2; Kobayashi et al., 2005; Schecterson et al., 2020). Similar to TRPV1, TRPA1-related mechanisms play a key role in the persistent tear reduction and symptoms of ocular discomfort observed in the rat model of DED (Katagiri et al., 2015). In addition to this, pretreatment with a TRPA1 antagonist (HC-030031) before the allergic challenge reduces the mechanical threshold of polymodal nociceptors, tend to attenuate the enhanced response de $\mathrm{CO}_{2}$ and reverse the enhanced blinking in an animal model of allergic keratoconjunctivitis (Table 1; Acosta et al., 2013). With HC-030031 treatment, as well as in TRPA1 ${ }^{-/-}$knockout mice, $^{-}$ it has been reported a decrease in macrophage infiltration, stromal neovascularization and corneal fibrosis in a mouse model of corneal injury. Inhibition of the TGF- $\beta 1$ signaling pathway in fibroblasts with the loss or blockade of TRPA1 would explain, in part, its role in corneal repair. Therefore, TRPA1 represents a potential therapeutic target for corneal lesions and ocular infections associated to inflammatory fibrosis that can lead to vision loss if not treated properly (Okada et al., 2015).

\subsection{Acid-Sensing lon Channels}

The Acid-Sensing Ion Channel (ASIC) family belong to the $\mathrm{ENaC} /$ Degenerin (DEG) ion channel superfamily which in rodents is composed by at least six different subunits (ASIC1a, ASIC1b, ASIC2a, ASIC2b, ASIC3, and ASIC4) encoded by four genes (accn1-4) (Kellenberger and Schild, 2015). In humans, this ion channel family is expanded by the expression of three and two splice variants for ASIC3 and ASIC4, respectively. However, expression of ASIC1b mRNA has never been identified. Evidence using x-ray crystallography (Jasti et al., 2007) and atomic force microscopy (Carnally et al., 2008) have revealed that functional ASIC channels are arranged as homo- and heterotrimeric channels where specific subunit composition confer different biophysical and pharmacological properties to an ASIC trimer (Hesselager et al., 2004). They are voltageindependent, ligand-gated cation channels mainly permeable to $\mathrm{Na}^{+}$(although ASICla homomers are also permeable to $\mathrm{Ca}^{2+}$ (Waldmann et al., 1997) activated by extracellular protons and different nonproton ligands (Kellenberger and Schild, 2015; Vullo and Kellenberger, 2019). Not all ASIC subunits can form proton-gated functional channels, for instance, ASIC2b and ASIC4 do not form proton-sensitive homomeric channels but the can interact with other ASIC subunits modulating their ion channel properties and kinetics in response to extracellular acidosis (Hesselager et al., 2004). All ASIC subunits have been detected in DRG and TG neurons from mouse and human tissues (although ASIC4 shows a weak expression) (Zeisel et al., 2018; Nguyen et al., 2017; Flegel et al., 2015; Hockley et al., 2019; Schuhmacher and Smith, 2016), including neurons that innervate the cornea in mice (Figure 2; Callejo et al., 2015). Due to their ability to detect increasing proton concentrations in the extracellular environment, they have been involved in many physiological and pathological processes such as synaptic plasticity, learning and memory, fear conditioning, pain, migraine, epileptic seizures and ischemic stroke (Wemmie et al., 2013; Deval and Lingueglia, 2015; Dussor, 2015; Kellenberger and Schild, 2015; Lee and Chen, 2018; Vullo and Kellenberger, 2019).

As mentioned above, a decrease in $\mathrm{pH}$ in the tear film covering the anterior ocular surface induces a nociceptive response in animal models and irritation and burning sensation, and to a lesser extent stinging pain, in humans (Chen et al., 1997; Belmonte et al., 1999; Acosta et al., 2001b; Feng and Simpson, 2003; Callejo et al., 2015). These sensations are evoked by the activation of polymodal nociceptive fibers innervating the cornea and conjunctiva (Chen et al., 1995; Belmonte et al., 1999). Initial studies performed to characterize the molecular identity of acid sensors in the cornea demonstrated that after $\mathrm{CO}_{2}$-mediated acidic stimulation with $\mathrm{CO}_{2}$ to the cat cornea, $50 \%$ of polymodal fibers responding to acid also responded to the TRPV1 agonist capsaicin. These fibers were also blocked by the TRPV1 antagonist capsazepine (Chen et al., 1997), indicating the role of this ion channel in the detection of proton ion concentrations in the cornea. However, the existence of acid-sensitive polymodal fibers that do not respond to capsaicin, suggests the functional expression of others ion channels/receptors capable of detecting extracellular 
acidosis in the anterior ocular surface. Besides TRPV1, ASICs have been identified as detectors of acidic stimuli in sensory neurons innervating the cornea (Figure 2; Callejo et al., 2015). TRPV1 and ASIC channels differ in their $\mathrm{pH}$ sensitivities, whereas TRPV1 is activated at lower $\mathrm{pH}$ values $(\mathrm{pH} 6.4$ or below), ASIC channels can detect moderate changes in $\mathrm{pH}$ (between $\mathrm{pH} 7.4$ and 6). Moderate acidic stimulation $(\mathrm{pH}=$ 6.6) induces depolarization and action potential (AP) firing in a subpopulation of corneal neurons in culture (Callejo et al., 2015). This $\mathrm{pH}$-evoked neuronal firing is abolished by the pretreatment with specific ASIC antagonists such as toxins PcTx1 and APETx2, which inhibit homomeric ASIC1a channels and ASIC3containing channels, respectively. It is worth mentioning that only $14 \%$ of neurons that respond to acid are blocked by PcTx1, whereas APETx2 abolishes the AP firing of the remaining acid responders (86\%). This difference could be explained by the expression of different ASIC subunits in the same corneal neuron and a wider range of inhibition of APETx2, which blocks all ASIC3-containing channels. Accordingly, voltageclamp recordings of corneal neurons in response to moderate acidic $\mathrm{pH}$ showed currents with biophysical and pharmacological characteristics of homomeric ASICla, homomeric ASIC3 and/or heteromeric ASIC1/3 channels. Moreover, the application of moderate acidic solutions in the rat cornea induces nocifensive behaviors (blinking and scratching) that can be partially prevented with selective and non-selective ASIC antagonists (Callejo et al., 2015). In contrast, the application of a specific ASIC3 agonist (2-guanidine-4-methylquinazoline, GMQ), that can activate ASIC3 at physiological $\mathrm{pH}$, enhances the AP firing rate of corneal sensory fibers and increases the blinking and tearing rate in guinea pigs (Callejo et al., 2015). Altogether, these data suggest that ASIC channels are important proton sensors in the ocular surface, where they are functionally expressed, and crucially participate in the detection of moderate acidifications applied to the cornea and the consequent transduction to painful sensation.

ASIC channel inhibition has been proven effective to ameliorate pain in different animal models of inflammation, where specific inhibition leads to a reduced nocifensive behavior in animals after mechanical and chemical stimulation of the inflamed tissues (Deval et al., 2008; Karczewski et al., 2010; Walder et al., 2010; Deval et al., 2011). Particularly in the eye, ASICs have been involved in a model of allergic keratoconjunctivitis (Table 1; Callejo et al., 2015). In this model, the inhibition of ASIC3-containing channels by APETx2 did not prevent the nocifensive behaviors triggered by the application of an acidic solution ( $\mathrm{pH} 5$ ) on the ocular surface, however, APETx 2 treatment reduced the blinking rate of animals exposed to the allergen when a solution at physiological $\mathrm{pH}$ was applied. Moreover, whole-cell recordings of labelled TG corneal neurons derived from these animals showed an increase in ASIC current density that was partially inhibited by APETx2 (Callejo et al., 2015). Taking together, these results indicate that ASIC channels play an important role in the development of ocular inflammation and sensitization after an allergic challenge.

\subsection{Two-Pore Domain Potassium Channels $\left(\mathrm{K}_{\mathbf{2 P}} \mathbf{S}\right)$}

The family of $\mathrm{K}_{2 \mathrm{P}} \mathrm{K}^{+}$channels was the last one identified and described, which has 15 members grouped into six subfamilies (TWIK, TREK, TASK, TALK, THIK, and TRESK) based on sequence and functional similarities (Enyedi and Czirják, 2010). The first $K_{2 P}$ channel identified was TWIK1, for Tandem of pore domains in a Weak Inward-rectifying $\mathrm{K}^{+}$ channel. Now, this subfamily also contains TWIK2 and KCNK7 (K $\left.\mathrm{K}_{2 \mathrm{P}} 7.1\right)$. The TREK (TWIK-RElated $\mathrm{K}^{+}$channel) subfamily contains TREK1, TREK2, and TRAAK (TWIKRelated Arachidonic acid Activated $\mathrm{K}^{+}$) channels. Members of this subfamily are activated by arachidonic acid, polyunsaturated fatty acids (PUFAs), volatile anesthetics, and pain-related stimuli. The TASK (TWIK-related Acid-Sensitive $\mathrm{K}^{+}$channel) subfamily contains TASK1, TASK3, and TASK5 ( $\left.\mathrm{K}_{2 \mathrm{P}} 15.1, \mathrm{KCNK} 15\right)$, and these channels have the common property of being inhibited by extracellular acidification. The TALK (TWIK-related ALkaline $\mathrm{pH}$-activated channel) subfamily includes TALK1, TALK2 $\left(\mathrm{K}_{2 \mathrm{P}} 17.1, \mathrm{KCNK} 17\right)$ and TASK2 and they have an important role in sensing extracellular alkaline pH. THIK1 and THIK2 conform the THIK (Tandem pore domain Halothane-Inhibited $\mathrm{K}^{+}$) channel subfamily and both channels are inhibited by halothane. The last subfamily identified was TRESK (TWIKRElated Spinal cord $\mathrm{K}^{+}$) that has only one member, TRESK $\left(\mathrm{K}_{2 \mathrm{P}} 18, \mathrm{KCNK} 18\right)$, with the lowest structural and functional similarity to other $\mathrm{K}_{2 \mathrm{P}}$ channels. This channel is the only one in the family being regulated by the intracellular $\mathrm{Ca}^{2+}$ concentration through calcineurin-mediated dephosphorylation.

The main role attributed to $K_{2 \mathrm{P}}$ channels in most cell types is the regulation of membrane potential, as they constitute the leak of potassium through the plasma membrane. Therefore, they are commonly refereed as leak or background potassium channels and their function, together with the $\mathrm{Na}^{+} / \mathrm{K}^{+}$pump, helps to set the resting membrane potential. $\mathrm{K}_{2 \mathrm{P}}$ channels are the main sustained $\mathrm{K}^{+}$conductance that establish the resting membrane potential in neurons, influencing neuronal excitability over a wide range of membrane potentials, especially between resting and action potential threshold, and shaping the duration, frequency and amplitude of the action potential. Basic biophysical properties of this family of channels, regulation, and interaction with other proteins are reviewed elsewhere, including some comprehensive and extensive reviews (Enyedi and Czirják, 2010; Busserolles et al., 2019).

Almost all $\mathrm{K}_{2 \mathrm{P}}$ channels are expressed in DRG and TG neurons but the relative expression of each channel varies between different neuronal populations and species. In humans, the most prevalent channels in DRG and TG are THIK-2, TASK1 and TWIK1, followed by TREK1, TASK2 and TRESK (Flegel et al., 2015). Other studies found TRESK as the most expressed channel in human TG (Medhurst et al., 2001; LaPaglia et al., 2018). In mouse and rat sensory neurons, TRESK, TRAAK, TREK2, TREK1, TWIK1, and TWIK2 are the most highly expressed channels although relative expression may vary between studies. Interestingly, mutations in TRESK have been involved in pain derived from familial migraine with aura 
(Lafrenière et al., 2010). This effect is thought to be mediated by non-functional homomeric TRESK channels and heteromeric TRESK/TREK1 or TRESK/TREK2 channels, which enhances trigeminal nociceptors excitability and triggers migraine pain (Royal et al., 2019).

As mentioned, it is known that sensory neurons in the trigeminal ganglia express some of these channels but, at the ocular level, no detailed characterization of the channel types expressed in sensory neurons exist to date. Nevertheless, transcriptomic data indicates that TRESK is enriched in TG compared to DRGs and the presence of TREK1 and TREK2 has also been shown in the TG (Yamamoto et al., 2009; Nguyen et al., 2017; LaPaglia et al., 2018). In particular, TREK1, TREK2 and TRAAK are expressed in small-medium diameter trigeminal neurons (likely nociceptors) which show a significant overlap with TRPV1 expression (Yamamoto et al., 2009). In contrast, poor colocalization of these channels is shown with TRPV2 or TRPM8 in trigeminal neurons, with only small colocalization of TREK1 and TRPM8 in some cells (Yamamoto et al., 2009). In this sense, transcriptomic studies have shown that TRPM8-positive trigeminal neurons express TASK3 and, to a lesser extent, TREK1 (Morenilla-Palao et al., 2014). Therefore, it is likely that nociceptive and thermoreceptive sensory neurons specifically innervating the ocular surface present $\mathrm{K}_{2 \mathrm{P}}$ expression. The members of the TREK subfamily of channels are modulated by changes in $\mathrm{pH}$. The most studied channel, TREK1, in addition to its activation by arachidonic acid and mechanical stimuli, it is also modulated by changes in $\mathrm{pH}$. Intracellular acidification activates the channel and, in addition, enhances channel activity in response to other stimuli, such as membrane stretch (Maingret et al., 1999). Also, extracellular stimuli that induce a decrease in intracellular $\mathrm{pH}$ such as bicarbonate $\left(\mathrm{HCO}_{3}{ }^{-}\right)$or $\mathrm{CO}_{2}$, produce the same effects (Chen et al., 1997; Lee and Chen, 2018). Whether $\mathrm{CO}_{2}$ application to the ocular surface produces an intracellular acidification in sensory nerve terminals it is not known. Nevertheless, if this occurs, TREK1 activation would hyperpolarize the terminal, thus preventing action potential firing. Nevertheless, extracellular acidification strongly inhibits TREK1 and activates TREK2, another closely related channel (Sandoz et al., 2009). These effects are due to histidines H126 and H151 in the extracellular loop of TREK1 and TREK2, respectively, that act as proton sensors. This extracellular regulation of TREK1 would depolarize the cell by inhibiting its potassium current. This might occur in the ocular surface when acidic sensitivity is tested by application of low $\mathrm{pH}$ solutions or acetic acid (Belmonte et al., 1991; Callejo et al., 2015). TRESK is also regulated by $\mathrm{pH}$ and both extracellular and intracellular acidification inhibit the channel current while alkalinization slightly enhances the channel activity (Sano et al., 2003; Callejo et al., 2013). Despite no clear demonstration is available to date, it is possible that combined inhibition of TREK1 and TRESK by extracellular acidification of the ocular surface reduces channels activity and promotes nociceptor terminals depolarization and firing or, at least, facilitates their activation by other stimuli.

$\mathrm{K}_{2 \mathrm{P}}$ channels TASK3, TREK1, and TASK2 have been also found in cold-sensitive TRPM8 ${ }^{+}$sensory neurons (Morenilla-
Palao et al., 2014). The ocular surface, particularly the cornea, present a high innervation by these neurons which, in addition to detect changes in temperature in the cold range, are involved in the regulation of basal tearing rate and the detection of osmolarity changes and ocular dryness (Parra et al., 2010; Belmonte and Gallar, 2011; Quallo et al., 2015). As mentioned before, two subclasses can be distinguished in the population of corneal cold thermoreceptor neurons: a larger population of lowthreshold cold thermoreceptors (high TRMP8 expression) and a smaller population of high-threshold cold thermoreceptors (low TRPM8 expression). This last population comprises about $30 \%$ of the ocular cold-thermoreceptors and are silent until strong cooling activates them, probably acting as cold nociceptors (Belmonte, 2019). TASK3 is highly expressed in about $30 \%$ of these neurons and its activity is highly sensitive to acidification (Kim et al., 2000). The sensitivity of TRPM8 sensory neurons to cold or to TRPM8 agonists (e.g., menthol) is enhanced in the absence of TASK 3 or by inhibiting the channel with an acidic solution ( $\mathrm{pH}$ 6). Interestingly, deletion of TASK3 in mice eliminates the population of high-threshold cold thermoreceptors, indicating that the channel plays a significant role in setting the temperature threshold of these neurons. Therefore, TASK3, together with Kv1, can be acting as a brake in excitability, dampening the sensitivity to cold temperatures of high-threshold, cold-sensitive nociceptive neurons (Madrid et al., 2009; Morenilla-Palao et al., 2014). Whether a simple pH change, without the temperature drop, can activate these neurons has not been tested.

\subsection{Other Receptors}

\subsubsection{Proton-Sensing G Protein-Coupled Receptors}

On top of the proton-activated ion channels described above, the sensitivity to acid has been described for other ion channels and receptors. Several G protein-coupled receptors (GPCRs) engage heteromeric $G$ proteins in response to acidic stimuli and were termed accordingly as proton-sensing GPCRs (PS-GPCRs). The group of PS-GPCRs is formed by six receptors; the initially described GPR4, GPR65 (TDAG8, T-cell death-associated gene 8), GPR68 (OGR1, Ovarian cancer G protein-coupled receptor 1), and GPR132 (G2A) (Ludwig et al., 2003; Murakami et al., 2004; Wang et al., 2004), together with the recently identified GPR31 and GPR151 (Mashiko et al., 2019). Conserved histidines localized in their extracellular domain confer them the ability to be activated by acidic stimuli in the $\mathrm{pH}$ range of 7.6-5.6 (Ludwig et al., 2003; Ishii et al., 2005), however, they also can be modulated by other endogenous and exogenous molecules such as lipids (Murakami et al., 2004; Wang et al., 2004) and synthetic ligands (Ludwig et al., 2003). Upon activation they engage different intracellular signaling pathways linked to the function of different $G$ proteins, including stimulation of inositol phosphate or cAMP production. Due to their ability to sense extracellular acidification, different studies have investigated their role in inflammatory mouse models. The expression of GPR4, GPR65, and GPR132 is upregulated in several mouse models of inflammatory pain (Chen et al., 2009; Dai et al., 2017). Several studies have shown that ablating the function of these receptors, by pharmacological or transgenic approaches, reduces persistent 
pathological pain from inflammatory and neuropathic origin (Dai et al., 2017; Hsieh et al., 2017; Miltz et al., 2017). However, although their role as acid sensors and their involvement in inflammatory conditions have been demonstrated, their expression in sensory fibers innervating the ocular surface has never been determined, and therefore, their role in the detection of acidic insults and inflammatory conditions affecting the cornea and conjunctiva remains to be studied.

\subsubsection{Purinergic P2X Receptors}

Purinergic P2X receptors are another group of ion channels gated by ATP or other purinergic derivatives, but protons act as allosteric modulators modulating the activation and function of these receptors (Coddou et al., 2011). The potency of activation of $\mathrm{P}_{2} \mathrm{X}_{2}$ by specific agonists is enhanced 5- to 10fold by acidification and even small changes in extracellular $\mathrm{pH}$ (7.1-7.2), enhance the response of $\mathrm{P}_{2} \mathrm{X}_{2 / 3}$ heteromeric receptors. In contrast, acidification inhibits most of the homomeric P2X receptors. In particular, in some studies, $\mathrm{P}_{2} \mathrm{X}_{3}$ is slightly inhibited by acidification but in other $\mathrm{P} 2 \mathrm{X}$ subtypes, acidic $\mathrm{pH}$ exerts a dual effect, shifting the concentration-response curve to the right but increasing the current amplitude and activation time constant. Almost all P2X receptors have been detected in the trigeminal ganglia of both human and rodent species (Manteniotis et al., 2013; Flegel et al., 2015). $\mathrm{P}_{2} \mathrm{X}_{3}$ receptor is mainly expressed in sensory ganglia and mRNA and protein is found in the cell bodies of both small and large trigeminal sensory neurons but has the highest level of expression among smaller neurons, specially, in non-peptidergic IB4 ${ }^{+}$neurons (Staikopoulos et al., 2007). $\mathrm{P} 2 \mathrm{X}_{4}$, $\mathrm{P}_{2} \mathrm{X}_{5}$, and $\mathrm{P} 2 \mathrm{X}_{6}$ also show significant levels of expression in the trigeminal ganglia and lower levels are found for $\mathrm{P} 2 \mathrm{X}_{1}, \mathrm{P} 2 \mathrm{X}_{2}$ (Flegel et al., 2015). Despite the studies in trigeminal ganglion neurons, and like PS-GPCRs, there is a lack of specific studies on purinergic receptors in the sensory nerve endings innervating the anterior part of the eye (cornea, sclera and conjunctiva) thus the role of protons modulating purinergic signaling remains to be properly studied.

\subsection{Ion Channels in Ocular Non-Neuronal Cells}

In addition to the proton-sensing ion channels expressed in peripheral nerves innervating the cornea or the conjunctiva, cells from the corneal epithelium, endothelium or the conjunctiva also express ion channels with important functions for ocular physiology. Members of the TRP family have also been identified in corneal cells, including TRPV1-4, TRPM8, TRPA1, or TRPC4 (Mergler et al., 2014). TRPV1 has been found in the epithelium, stroma and endothelium of the cornea (Yang et al., 2013a; Mergler et al., 2014). In the epithelium, TRPV1 activation leads to an increase in intracellular calcium that induces inflammatory cytokine release through MAPK (mitogen-activated protein kinase) signaling (Zhang et al., 2007), thus it appears that TRPV1 has a significant role in infiltration of inflammatory mediators in the corneal epithelium and stroma. The channel has been also involved in cell migration and proliferation, thus promoting corneal epithelial wound healing response. Because TRPV1 is sensitive to protons, it is likely that acidification contributes to ocular surface inflammation though this channel, promoting the release of interleukins and other inflammatory mediators.

\section{ACIDIC SUBSTANCES AND COMMERCIAL DRUGS}

A chemical injury with an acidic substance on the ocular surface is a medical emergency that must be evaluated and treated immediately. The treatment is usually based on reestablishing corneal clarity, recovering the ocular surface and avoiding increased intraocular pressure and damage to the optic nerve to prevent visual impairment. In contact with the cornea, acidic substances $(\mathrm{pH}<4)$ denature and precipitate proteins, and their coagulation produces the opacity of the cornea that characterizes severe acid burns. After the acidic injury, the recovery phase begins in which the corneal epithelium and the stroma are restored, inflammatory mechanisms become evident on the ocular surface and there is stromal ulceration and corneal scarring (Singh et al., 2013). The main early signs of an acid burn in the eye include ocular pain and irritation, increased tear secretion, swollen eyelids and blurred vision. TRPV1 and ASICs, activated by low $\mathrm{pH}$, are the main channels that mediate eye pain after acid injury. Hence, decreased expression or blocking of TRPV1 reduces pain caused by chemical injuries at the cornea (Moreno-Montañés et al., 2018; Hatta et al., 2019). In addition to mediate pain responses, TRPV1 is involved in the release of proinflammatory cytokines after an injury of corneal epithelial cells. Therefore, it is a good candidate to control eye pain in corneal injuries and inflammatory responses in the wound healing process (Yang et al., 2013b). As mentioned above, TRPA1 has also been associated with corneal regeneration after chemical injuries (Okada et al., 2015).

A number of compounds used to treat eye diseases are formulated in acidic solutions to facilitate their solubilization and absorption through the cornea. Ocular topical application of these drugs can cause adverse side effects associated with irritation and toxicity of the corneal surface (Zhang et al., 2019). Dorzolamide hydrochloride (Trusopt ${ }^{\circledR}$ as tradename), which is a carbonic anhydrase inhibitor indicated to treat ocular hypertension and primary open-angle glaucoma, has a $\mathrm{pH}$ value of 5.6 and usually causes ocular irritation in patients (Konowal et al., 1999; Gordon et al., 2008). Other compounds with low $\mathrm{pH}$ values used as commercial ophthalmic eye drops to treat glaucoma are the non-selective $\beta$-blocker levobunolol hydrochloride (Betagan ${ }^{\circledR} \mathrm{pH}_{\circledast}$ 6.5) and the prostaglandin analog latanoprost (Xalatan , Mylan ${ }^{\circledR}$, Travatan $^{\circledR}$, Saflutan ${ }^{\circledR}$, Cosopt ${ }^{\circledR} ; \mathrm{pH}$ values between 5.6 and 6.7). It is widely known that they cause temporary burning, redness, itching and blurred vision (Thygesen, 2018). Consistent with this, $\mathrm{pH}$ neutralization in some ophthalmic compounds abolishes ocular irritation associated with their use (Loftsson et al., 2012). In this sense, previous studies have shown that ASICs participate in the nociceptive responses produced by Mylan ${ }^{\circledR}$ and Betagan ${ }^{\circledR}$, and 
probably also by Trusopt ${ }^{\circledast}$ (Callejo et al., 2015). The low pH of this last compound, as well as its lower osmolarity and high viscosity might involve the activation of TRPV1 and other mechanisms, thus ASIC blockers are not sufficient to decrease its irritative effect (Callejo et al., 2015). At this point, identification and characterization of ion channels and the molecular mechanisms mediating ocular discomfort caused by ophthalmic drugs is essential to try to avoid undesirable side effects.

\section{SUMMARY}

The ocular surface is a particular structure of the body greatly exposed to external environment and to many irritative and painful stimuli. This is probably the reason why the cornea presents the highest sensory innervation of the body, which allows to detect potentially damaging stimuli and to respond accordingly with protective behaviors such as blinking or tearing. Several mechanical, chemical or thermal stimuli are known to activate corneal, conjunctival and scleral peripheral terminals of trigeminal sensory neurons (particularly, nociceptors). Among them, acidic stimuli are known induce firing of polymodal nociceptors through activation of specific ion channels in these neurons. Part of these responses are mediated by members of the ASIC family, as about $2 / 3$ of corneal sensory neurons present ASIC-like currents. Specifically, homomeric ASIC1a, ASIC3 and heteromeric ASIC1/3 channels have been identified (Callejo et al., 2015). These channels are activated by moderate acidifications $(\mathrm{pH} 7.2-6.6)$ that can occur in the ocular surface during inflammation or allergic conditions, in addition to insults from external acidic solutions. In this sense, ASIC also contribute to nociceptor sensitization and pain during allergic keratoconjunctivitis, as blockade of ASIC3 channels diminish nocifensive behavior in rodent models (Callejo et al., 2015). Interestingly, in addition to protons, other compounds such as GMQ is able to activate ASIC3 in the ocular surface, inducing nocifensive behaviors (blinking and tearing), as well as firing of ocular sensory nerve fibers. Other members of the family such as ASIC1b, ASIC2a and ASIC2b are also probably present in ocular nociceptors, as expression has been found in the trigeminal ganglion (Callejo et al., 2015). Nevertheless, no clear identification in ocular sensory neurons has been provided to date.

Another channel long involved in acid sensing is TRPV1, as this channel is directly activated by protons (Tominaga et al., 1998). Despite moderate acidifications (pH 6-7) enhance the responses to capsaicin and heat, the channel needs stronger

\section{REFERENCES}

Acosta, M. C., Belmonte, C., and Gallar, J. (2001). Sensory Experiences in Humans and Single-Unit Activity in Cats Evoked by Polymodal Stimulation of the Cornea. J. Physiol. 534 (Pt 2), 511-525. doi:10.1111/j.1469-7793.2001.t01-1-00511.x

Acosta, M. C., Luna, C., Quirce, S., Belmonte, C., and Gallar, J. (2013). Changes in Sensory Activity of Ocular Surface Sensory Nerves during Allergic acidifications $(\mathrm{pH}<6)$ to be directly gated by protons (Tominaga et al., 1998). These biophysical properties seem to indicate that it is unlikely that acidification occurring during ocular inflammation or allergy can directly activate the channel but, certainly, can enhance its response to heat or other compounds, thus intensifying painful sensations. In fact, blocking TRPV1 or TRPA1 with specific antagonists or siRNAs has been demonstrated to reduce polymodal nociceptors activity and ocular surface irritation by exogenous compounds or during allergic keratoconjunctivitis (Luna et al., 2007; Acosta et al., 2013). Besides, ASICs seem more prone to mediate the acidic responses to moderate acidifications. Nevertheless, important exogenous acidic insults are likely to activate both types of channels, thus a major activation of sensory nerve terminals will be achieved.

The contribution of other channels and receptors that are likely expressed in corneal or conjunctival nerve fibers are poorly studied to date. Some of these, such as $\mathrm{K}_{2 \mathrm{P}}$ channels can have a significant influence in the excitability of ocular sensory fibers, modulating their excitability and, in consequence, pain sensitivity. Because these potassium channels are polymodal integrators, like TRPV1 and TRPA1, different stimuli including protons, can modulate their activity to enhance or diminish nociceptive input.

Despite some of the mechanisms of proton sensing in the ocular surface are becoming to be elucidated, specific studies on the different types of channels or receptors involved are needed, as well as the different types of sensory fibers involved.

\section{AUTHOR CONTRIBUTIONS}

All authors listed have made a substantial, direct, and intellectual contribution to the work and approved it for publication.

\section{FUNDING}

This research was funded by European Union, Fondo Europeo de Desarrollo Regional (FEDER), Ministerio de Ciencia e Innovación and Instituto de Salud Carlos III of Spain, FIS P17/00296 (XG), RETICs Oftared RD16/0008/0014 (XG). Research project PID 2020-119305RB-100 (XG and NC) funded by MCIN/AEI/ 10.13039/501100011033. Molecule-to-man pain network (PainNet, 721841) MSCA-ITN-2016-Innovative Training Networks (XG). Generalitat de Catalunya 2017SGR737 (XG) and María de Maeztu MDM-2017-0729 to Institut de Neurociències, Universitat de Barcelona.

Keratoconjunctivitis. Pain 154 (11), 2353-2362. doi:10.1016/ j.pain.2013.07.012

Acosta, M. C., Luna, C., Quirce, S., Belmonte, C., and Gallar, J. (2014). Corneal Sensory Nerve Activity in an Experimental Model of UV Keratitis. Invest. Ophthalmol. Vis. Sci. 55 (6), 3403-3412. doi:10.1167/iovs.13-13774

Acosta, M. C., Tan, M. E., Belmonte, C., and Gallar, J. (2001). Sensations Evoked by Selective Mechanical, Chemical, and thermal Stimulation of the Conjunctiva and Cornea. Invest. Ophthalmol. Vis. Sci. 42 (9), 2063-2067. 
Alamri, A., Bron, R., Brock, J. A., and Ivanusic, J. J. (2015). Transient Receptor Potential Cation Channel Subfamily V Member 1 Expressing Corneal Sensory Neurons Can Be Subdivided Into at Least Three Subpopulations. Front. Neuroanat. 9, 71. doi:10.3389/fnana.2015.00071

Arvidson, B. (1977). Retrograde Axonal Transport of Horseradish Peroxidase from Cornea to Trigeminal Ganglion. Acta Neuropathol. 38 (1), 49-52. doi:10.1007/ BF00691276

Bandell, M., Story, G. M., Hwang, S. W., Viswanath, V., Eid, S. R., Petrus, M. J., et al. (2004). Noxious Cold Ion Channel TRPA1 is Activated by Pungent Compounds and Bradykinin. Neuron 41 (6), 849-857. doi:10.1016/s08966273(04)00150-3

Basbaum, A. I., Bautista, D. M., Scherrer, G., and Julius, D. (2009). Cellular and Molecular Mechanisms of Pain. Cell 139 (2), 267-284. doi:10.1016/ j.cell.2009.09.028

Bates, B. D., Mitchell, K., Keller, J. M., Chan, C. C., Swaim, W. D., Yaskovich, R., et al. (2010). Prolonged Analgesic Response of Cornea to Topical Resiniferatoxin, a Potent TRPV1 Agonist. Pain 149 (3), 522-528. doi:10.1016/j.pain.2010.03.024

Bautista, D. M., Jordt, S. E., Nikai, T., Tsuruda, P. R., Read, A. J., Poblete, J., et al. (2006). TRPA1 Mediates the Inflammatory Actions of Environmental Irritants and Proalgesic Agents. Cell 124 (6), 1269-1282. doi:10.1016/j.cell.2006.02.023

Belmonte, C., Acosta, M. C., Schmelz, M., and Gallar, J. (1999). Measurement of Corneal Sensitivity to Mechanical and Chemical Stimulation with a $\mathrm{CO} 2$ Esthesiometer. Invest. Ophthalmol. Vis. Sci. 40 (2), 513-519.

Belmonte, C., Aracil, A., Acosta, M. C., Luna, C., and Gallar, J. (2004). Nerves and Sensations from the Eye Surface. Ocul. Surf. 2 (4), 248-253. doi:10.1016/s15420124(12)70112-x

Belmonte, C., Gallar, J., Pozo, M. A., and Rebollo, I. (1991). Excitation by Irritant Chemical Substances of Sensory Afferent Units in the Cat's Cornea. J. Physiol. 437 (1), 709-725. doi:10.1113/jphysiol.1991.sp018621

Belmonte, C., Gallego, R., and Morales, A. (1988). Membrane Properties of Primary Sensory Neurones of the Cat After Peripheral Reinnervation. J. Physiol. 405 (1), 219-232. doi:10.1113/jphysiol.1988.sp017330

Belmonte, C., and Giraldez, F. (1981). Responses of Cat Corneal Sensory Receptors to Mechanical and thermal Stimulation. J. Physiol. 321, 355-368. doi:10.1113/ jphysiol.1981.sp013989

Belmonte, C. (2019). Pain, Dryness, and Itch Sensations in Eye Surface Disorders Are Defined by a Balance between Inflammation and Sensory Nerve Injury. Cornea 38 (Suppl. 1), S11-S24. doi:10.1097/ICO.0000000000002116

Belmonte, C., and Gallar, J. (2011). Cold Thermoreceptors, Unexpected Players in Tear Production and Ocular Dryness Sensations. Invest. Ophthalmol. Vis. Sci. 52 (6), 3888-3892. doi:10.1167/iovs.09-5119

Belmonte, C., Garcia-Hirschfeld, J., and Gallar, J. (1997). Neurobiology of Ocular Pain. Prog. Retin. Eye Res. 16 (1), 117-156. doi:10.1016/s1350-9462(96)00027-4

Belmonte, C., Tervo, T. T., and Gallar, J. (2011). Sensory Innervation of the Eye. Sect 5 Prot. Eye 2011, 363-384. doi:10.1016/b978-0-323-05714-1.00016-9

Benitez-Del-Castillo, J. M., Moreno-Montañés, J., Jiménez-Alfaro, I., MuñozNegrete, F. J., Turman, K., Palumaa, K., et al. (2016). Safety and Efficacy Clinical Trials for SYL1001, a Novel Short Interfering RNA for the Treatment of Dry Eye Disease. Invest. Ophthalmol. Vis. Sci. 57 (14), 6447-6454. doi:10.1167/ iovs.16-20303

Bereiter, D. A., Rahman, M., Thompson, R., Stephenson, P., and Saito, H. (2018). TRPV1 and TRPM8 Channels and Nocifensive Behavior in a Rat Model for Dry Eye. Invest. Ophthalmol. Vis. Sci. 59 (8), 3739-3746. doi:10.1167/iovs.18-24304

Bron, R., Wood, R. J., Brock, J. A., and Ivanusic, J. J. (2014). Piezo2 Expression in Corneal Afferent Neurons. J. Comp. Neurol. 522 (13), 2967-2979. doi:10.1002/ cne. 23560

Busserolles, J., Gasull, X., and Noël, J. (2019). Potassium Channels and Pain. Editor J. N. Wood (Oxford: Oxford University Press).

Cabanes, C., López de Armentia, M., Viana, F., and Belmonte, C. (2002). Postnatal Changes in Membrane Properties of Mice Trigeminal Ganglion Neurons. J. Neurophysiol. 87 (5), 2398-2407. doi:10.1152/jn.2002.87.5.2398

Callejo, G., Castellanos, A., Castany, M., Gual, A., Luna, C., Acosta, M. C., et al. (2015). Acid-sensing Ion Channels Detect Moderate Acidifications to Induce Ocular Pain. Pain 156 (3), 483-495. doi:10.1097/01.j.pain.0000460335.49525.17

Callejo, G., Giblin, J. P., and Gasull, X. (2013). Modulation of TRESK Background K+ Channel by Membrane Stretch. PLoS One 8 (5), e64471. doi:10.1371/ journal.pone.0064471
Carnally, S. M., Dev, H. S., Stewart, A. P., Barrera, N. P., Van Bemmelen, M. X., Schild, L., et al. (2008). Direct Visualization of the Trimeric Structure of the ASIC1a Channel, Using AFM Imaging. Biochem. Biophys. Res. Commun. 372 (4), 752-755. doi:10.1016/j.bbrc.2008.05.100

Caterina, M. J., Leffler, A., Malmberg, A. B., Martin, W. J., Trafton, J., PetersenZeitz, K. R., et al. (2000). Impaired Nociception and Pain Sensation in Mice Lacking the Capsaicin Receptor. Science 288 (5464), 306-313. doi:10.1126/ science.288.5464.306

Caterina, M. J., Schumacher, M. A., Tominaga, M., Rosen, T. A., Levine, J. D., and Julius, D. (1997). The Capsaicin Receptor: A Heat-Activated Ion Channel in the Pain Pathway. Nature 389 (6653), 816-824. doi:10.1038/39807

Chen, X., Belmonte, C., and Rang, H. P. (1997). Capsaicin and Carbon Dioxide Act by Distinct Mechanisms on Sensory Nerve Terminals in the Cat Cornea. Pain 70 (1), 23-29. doi:10.1016/s0304-3959(96)03256-3

Chen, X., Gallar, J., Pozo, M. A., Baeza, M., and Belmonte, C. (1995). CO2 Stimulation of the Cornea: A Comparison between Human Sensation and Nerve Activity in Polymodal Nociceptive Afferents of the Cat. Eur. J. Neurosci. 7 (6), 1154-1163. doi:10.1111/j.1460-9568.1995.tb01105.x

Chen, Y.-J., Huang, C.-W., Lin, C.-S., Chang, W.-H., and Sun, W.-H. (2009). Expression and Function of Proton-Sensing G-Protein-Coupled Receptors in Inflammatory Pain. Mol. Pain 5 (1), 1744-8069. doi:10.1186/1744-8069-5-39

Chiu, I. M., Barrett, L. B., Williams, E. K., Strochlic, D. E., Lee, S., Weyer, A. D., et al. (2014). Transcriptional Profiling at Whole Population and Single Cell Levels Reveals Somatosensory Neuron Molecular Diversity. eLife 3, e04660. doi:10.7554/eLife.04660

Clapham, D. E. (2003). TRP Channels as Cellular Sensors. Nature 426 (6966), 517-524. doi:10.1038/nature02196

Coddou, C., Yan, Z., Obsil, T., Huidobro-Toro, J. P., and Stojilkovic, S. S. (2011). Activation and Regulation of Purinergic P2X Receptor Channels. Pharmacol. Rev. 63 (3), 641-683. doi:10.1124/pr.110.003129

Cordero-Morales, J. F., Gracheva, E. O., and Julius, D. (2011). Cytoplasmic Ankyrin Repeats of Transient Receptor Potential A1 (TRPA1) Dictate Sensitivity to thermal and Chemical Stimuli. Proc. Natl. Acad. Sci. U.S.A. 108 (46), E1184-E1191. doi:10.1073/pnas.1114124108

Dai, S. P., Huang, Y. H., Chang, C. J., Huang, Y. F., Hsieh, W. S., Tabata, Y., et al. (2017). TDAG8 Involved in Initiating Inflammatory Hyperalgesia and Establishing Hyperalgesic Priming in Mice. Sci. Rep. 7 (1), 41415. doi:10.1038/srep41415

Dai, Y., Wang, S., Tominaga, M., Yamamoto, S., Fukuoka, T., Higashi, T., et al. (2007). Sensitization of TRPA1 by PAR2 Contributes to the Sensation of Inflammatory Pain. J. Clin. Invest. 117 (7), 1979-1987. doi:10.1172/JCI30951

Deval, E., and Lingueglia, E. (2015). Acid-Sensing Ion Channels and Nociception in the Peripheral and Central Nervous Systems. Neuropharmacology 94, 49-57. doi:10.1016/j.neuropharm.2015.02.009

Deval, E., Noël, J., Gasull, X., Delaunay, A., Alloui, A., Friend, V., et al. (2011). Acidsensing Ion Channels in Postoperative Pain. J. Neurosci. 31 (16), 6059-6066. doi:10.1523/JNEUROSCI.5266-10.2011

Deval, E., Noël, J., Lay, N., Alloui, A., Diochot, S., Friend, V., et al. (2008). ASIC3, a Sensor of Acidic and Primary Inflammatory Pain. EMBO J. 27 (22), 3047-3055. doi:10.1038/emboj.2008.213

Dussor, G. (2015). ASICs as Therapeutic Targets for Migraine. Neuropharmacology 94, 64-71. doi:10.1016/j.neuropharm.2014.12.015

Enyedi, P., and Czirják, G. (2010). Molecular Background of Leak K+ Currents: Two-Pore Domain Potassium Channels. Physiol. Rev. 90 (2), 559-605. doi:10.1152/physrev.00029.2009

Fakih, D., Guerrero-Moreno, A., Baudouin, C., Réaux-Le Goazigo, A., and Parsadaniantz, S. M. (2021). Capsazepine Decreases Corneal Pain Syndrome in Severe Dry Eye Disease. J. Neuroinflamm. 18 (1), 111. doi:10.1186/s12974021-02162-7

Feng, Y., and Simpson, T. L. (2003). Nociceptive Sensation and Sensitivity Evoked from Human Cornea and Conjunctiva Stimulated by CO2. Invest. Ophthalmol. Vis. Sci. 44 (2), 529-532. doi:10.1167/iovs.02-0003

Fernández-Trillo, J., Florez-Paz, D., Ínigo-Portugués, A., González-González, O., Del Campo, A. G., González, A., et al. (2020). Piezo2 Mediates Low-Threshold Mechanically Evoked Pain in the Cornea. J. Neurosci. 40 (47), 8976-8993. doi:10.1523/JNEUROSCI.0247-20.2020

Flegel, C., Schöbel, N., Altmüller, J., Becker, C., Tannapfel, A., Hatt, H., et al. (2015). RNA-seq Analysis of Human Trigeminal and Dorsal Root Ganglia with a Focus 
on Chemoreceptors. PLoS One 10 (6), e0128951. doi:10.1371/ journal.pone. 0128951

Gallar, J., Pozo, M. A., Tuckett, R. P., and Belmonte, C. (1993). Response of Sensory Units with Unmyelinated Fibres to Mechanical, thermal and Chemical Stimulation of the Cat's Cornea. J. Physiol. 468 (1), 609-622. doi:10.1113/ jphysiol.1993.sp019791

Gallar, J., Tervo, T. M., Neira, W., Holopainen, J. M., Lamberg, M. E., Miñana, F., et al. (2010). Selective Changes in Human Corneal Sensation Associated With Herpes Simplex Virus Keratitis. Invest. Ophthalmol. Vis. Sci. 51 (9), 4516-4522. doi:10.1167/iovs.10-5225

Gonzalez, G. G., Garcia de la Rubia, P., Gallar, J., and Belmonte, C. (1993). Reduction of Capsaicin-Induced Ocular Pain and Neurogenic Inflammation by Calcium Antagonists. Invest. Ophthalmol. Vis. Sci. 34 (12), 3329-3335.

González-González, O., Bech, F., Gallar, J., Merayo-Lloves, J., and Belmonte, C. (2017). Functional Properties of Sensory Nerve Terminals of the Mouse Cornea. Invest. Ophthalmol. Vis. Sci. 58 (1), 404-415. doi:10.1167/iovs.16-20033

Gordon, L. R., Bailly, Y., Durand-Cavagna, G., Delort, P., and Peter, C. P. (2008). Preclinical Ocular Irritation Findings With Dorzolamide Hydrochloride. J. Toxicol. Cutan. Ocul. Toxicol. 16 (1), 9-17. doi:10.3109/15569529709048884

Hatta, A., Kurose, M., Sullivan, C., Okamoto, K., Fujii, N., Yamamura, K., et al. (2019). Dry Eye Sensitizes Cool Cells to Capsaicin-Induced Changes in Activity via TRPV1. J. Neurophysiol. 121 (6), 2191-2201. doi:10.1152/jn.00126.2018

Hesselager, M., Timmermann, D. B., and Ahring, P. K. (2004). pH Dependency and Desensitization Kinetics of Heterologously Expressed Combinations of Acid-Sensing Ion Channel Subunits. J. Biol. Chem. 279 (12), 11006-11015. doi:10.1074/jbc.M313507200

Hockley, J. R. F., Taylor, T. S., Callejo, G., Wilbrey, A. L., Gutteridge, A., Bach, K., et al. (2019). Single-cell RNAseq Reveals Seven Classes of Colonic Sensory Neuron. Gut 68 (4), 633-644. doi:10.1136/gutjnl-2017-315631

Hsieh, W. S., Kung, C. C., Huang, S. L., Lin, S. C., and Sun, W. H. (2017). TDAG8, TRPV1, and ASIC3 Involved in Establishing Hyperalgesic Priming in Experimental Rheumatoid Arthritis. Sci. Rep. 7 (1), 8870. doi:10.1038/ s41598-017-09200-6

Huang, C. C., Kim, Y. S., Olson, W. P., Li, F., Guo, C., Luo, W., et al. (2016). A Histamine-independent Itch Pathway Is Required for Allergic Ocular Itch. J. Allergy Clin. Immunol. 137 (4), 1267-e6. doi:10.1016/j.jaci.2015.08.047

Huang, C. C., Yang, W., Guo, C., Jiang, H., Li, F., Xiao, M., et al. (2018). Anatomical and Functional Dichotomy of Ocular Itch and Pain. Nat. Med. 24 (8), 1268-1276. doi:10.1038/s41591-018-0083-x

Ishii, S., Kihara, Y., and Shimizu, T. (2005). Identification of T Cell DeathAssociated Gene 8 (TDAG8) as a Novel Acid Sensing G-Protein-Coupled Receptor. J. Biol. Chem. 280 (10), 9083-9087. doi:10.1074/jbc.M407832200

Jasti, J., Furukawa, H., Gonzales, E. B., and Gouaux, E. (2007). Structure of AcidSensing Ion Channel 1 at 1.9 A Resolution and Low pH. Nature 449 (7160), 316-323. doi:10.1038/nature06163

Jordt, S. E., Bautista, D. M., Chuang, H. H., McKemy, D. D., Zygmunt, P. M., Högestätt, E. D., et al. (2004). Mustard Oils and Cannabinoids Excite Sensory Nerve Fibres Through the TRP Channel ANKTM1. Nature 427 (6971), 260-265. doi:10.1038/nature02282

Karczewski, J., Spencer, R. H., Garsky, V. M., Liang, A., Leitl, M. D., Cato, M. J., et al. (2010). Reversal of Acid-Induced and Inflammatory Pain by the Selective ASIC3 Inhibitor, APETx2. Br. J. Pharmacol. 161 (4), 950-960. doi:10.1111/ j.1476-5381.2010.00918.x

Katagiri, A., Thompson, R., Rahman, M., Okamoto, K., and Bereiter, D. A. (2015). Evidence for TRPA1 Involvement in central Neural Mechanisms in a Rat Model of Dry Eye. Neuroscience 290, 204-213. doi:10.1016/j.neuroscience.2015.01.046

Kellenberger, S., and Schild, L. (2015). International Union of Basic and Clinical Pharmacology. XCI. Structure, Function, and Pharmacology of Acid-Sensing Ion Channels and the Epithelial Na+ Channel. Pharmacol. Rev. 67 (1), 1-35. doi:10.1124/pr.114.009225

Kim, Y., Bang, H., and Kim, D. (2000). TASK-3, a New Member of the Tandem Pore K(+) Channel Family. J. Biol. Chem. 275 (13), 9340-9347. doi:10.1074/ jbc.275.13.9340

Kobayashi, K., Fukuoka, T., Obata, K., Yamanaka, H., Dai, Y., Tokunaga, A., et al. (2005). Distinct Expression of TRPM8, TRPA1, and TRPV1 mRNAs in Rat Primary Afferent Neurons with Adelta/c-Fibers and Colocalization with Trk Receptors. J. Comp. Neurol. 493 (4), 596-606. doi:10.1002/cne.20794
Konowal, A., Morrison, J. C., Brown, S. V., Cooke, D. L., Maguire, L. J., Verdier, D. V., et al. (1999). Irreversible Corneal Decompensation in Patients Treated With Topical Dorzolamide. Am. J. Ophthalmol. 127 (4), 403-406. doi:10.1016/s00029394(98)00438-3

Lafrenière, R. G., Cader, M. Z., Poulin, J. F., Andres-Enguix, I., Simoneau, M., Gupta, N., et al. (2010). A Dominant-Negative Mutation in the TRESK Potassium Channel Is Linked to Familial Migraine with Aura. Nat. Med. 16 (10), 1157-1160. doi:10.1038/nm.2216

LaPaglia, D. M., Sapio, M. R., Burbelo, P. D., Thierry-Mieg, J., Thierry-Mieg, D., Raithel, S. J., et al. (2018). RNA-seq Investigations of Human Post-Mortem Trigeminal Ganglia. Cephalalgia 38 (5), 912-932. doi:10.1177/ 0333102417720216

Lee, C.-H., and Chen, C.-C. (2018). Roles of ASICs in Nociception and Proprioception. Adv. Exp. Med. Biol. 1099, 37-47. doi:10.1007/978-981-131756-9_4

Lennertz, R. C., Kossyreva, E. A., Smith, A. K., and Stucky, C. L. (2012). TRPA1 Mediates Mechanical Sensitization in Nociceptors during Inflammation. PLoS One 7 (8), e43597. doi:10.1371/journal.pone.0043597

Li, F., Yang, W., Jiang, H., Guo, C., Huang, A. J. W., Hu, H., et al. (2019). TRPV1 Activity and Substance P Release Are Required for Corneal Cold Nociception. Nat. Commun. 10 (1), 5678. doi:10.1038/s41467-019-13536-0

Lindsay, C. D., Green, C., Bird, M., Jones, J. T., Riches, J. R., McKee, K. K., et al. (2014). Potency of Irritation by Benzylidenemalononitriles in Humans Correlates With TRPA1 Ion Channel Activation. R. Soc. Open Sci. 2 (1), 140160. doi:10.1098/rsos. 140160

Liu, B., Escalera, J., Balakrishna, S., Fan, L., Caceres, A. I., Robinson, E., et al. (2013). TRPA1 Controls Inflammation and Pruritogen Responses in Allergic Contact Dermatitis. FASEB J. 27 (9), 3549-3563. doi:10.1096/fj.13-229948

Loftsson, T., Jansook, P., and Stefánsson, E. (2012). Topical Drug Delivery to the Eye: Dorzolamide. Acta Ophthalmol. 90 (7), 603-608. doi:10.1111/j.17553768.2011.02299.x

Logashina, Y. A., Korolkova, Y. V., Kozlov, S. A., and Andreev, Y. A. (2019). TRPA1 Channel as a Regulator of Neurogenic Inflammation and Pain: Structure, Function, Role in Pathophysiology, and Therapeutic Potential of Ligands. Biochemistry 84 (2), 101-118. doi:10.1134/\$0006297919020020

López de Armentia, M., Cabanes, C., and Belmonte, C. (2000). Electrophysiological Properties of Identified Trigeminal Ganglion Neurons Innervating the Cornea of the Mouse. Neuroscience 101 (4), 1109-1115. doi:10.1016/s0306-4522(00) 00440-1

Ludwig, M. G., Vanek, M., Guerini, D., Gasser, J. A., Jones, C. E., Junker, U., et al. (2003). Proton-sensing G-Protein-Coupled Receptors. Nature 425 (6953), 93-98. doi:10.1038/nature01905

Luna, C. L., Sesto, A., Acosta, M. C., Jimenez, M. C., Gallar, J., Belmonte, C., et al. (2007). TRPV1 siRNA Topical Treatment Reduces the Response to Ocular Surface Irritation with Capsaicin. Invest. Ophthalmol. Vis. Sci. 48 (5), 373.

Macpherson, L. J., Xiao, B., Kwan, K. Y., Petrus, M. J., Dubin, A. E., Hwang, S., et al. (2007). An Ion Channel Essential for Sensing Chemical Damage. J. Neurosci. 27 (42), 11412-11415. doi:10.1523/JNEUROSCI.3600-07.2007

Madrid, R., de la Peña, E., Donovan-Rodriguez, T., Belmonte, C., and Viana, F. (2009). Variable Threshold of Trigeminal Cold-Thermosensitive Neurons Is Determined by a Balance between TRPM8 and Kv1 Potassium Channels. J. Neurosci. 29 (10), 3120-3131. doi:10.1523/JNEUROSCI.4778-08.2009

Maingret, F., Patel, A. J., Lesage, F., Lazdunski, M., and Honoré, E. (1999). Mechano- or Acid Stimulation, Two Interactive Modes of Activation of the TREK-1 Potassium Channel. J. Biol. Chem. 274 (38), 26691-26696. doi:10.1074/jbc.274.38.26691

Manteniotis, S., Lehmann, R., Flegel, C., Vogel, F., Hofreuter, A., Schreiner, B. S. P., et al. (2013). Comprehensive RNA-Seq Expression Analysis of Sensory Ganglia with a Focus on Ion Channels and GPCRs in Trigeminal Ganglia. PLoS One 8 (11), e79523. doi:10.1371/journal.pone.0079523

Mashiko, M., Kurosawa, A., Tani, Y., Tsuji, T., and Takeda, S. (2019). GPR31 and GPR151 are Activated Under Acidic Conditions. J. Biochem. 166 (4), 317-322. doi:10.1093/jb/mvz042

Masuoka, T., Yamashita, Y., Nakano, K., Takechi, K., Niimura, T., Tawa, M., et al. (2020). Chronic Tear Deficiency Sensitizes Transient Receptor Potential Vanilloid 1-Mediated Responses in Corneal Sensory Nerves. Front. Cell Neurosci. 14, 598678. doi:10.3389/fncel.2020.598678 
Materazzi, S., Benemei, S., Fusi, C., Gualdani, R., De Siena, G., Vastani, N., et al. (2013). Parthenolide Inhibits Nociception and Neurogenic Vasodilatation in the Trigeminovascular System by Targeting the TRPA1 Channel. Pain 154 (12), 2750-2758. doi:10.1016/j.pain.2013.08.002

Medhurst, A. D., Rennie, G., Chapman, C. G., Meadows, H., Duckworth, M. D., Kelsell, R. E., et al. (2001). Distribution Analysis of Human Two Pore Domain Potassium Channels in Tissues of the central Nervous System and Periphery. Brain Res. Mol. Brain Res. 86 (1-2), 101-114. doi:10.1016/s0169-328x(00) 00263-1

Mergler, S., Valtink, M., Takayoshi, S., Okada, Y., Miyajima, M., Saika, S., et al. (2014). Temperature-Sensitive Transient Receptor Potential Channels in Corneal Tissue Layers and Cells. Ophthalmic Res. 52 (3), 151-159. doi:10.1159/000365334

Messmer, E. M. (2015). The Pathophysiology, Diagnosis, and Treatment of Dry Eye Disease. Dtsch. Arztebl. Int. 112 (5), 71-81; quiz 82. doi:10.3238/ arztebl.2015.0071

Miltz, W., Velcicky, J., Dawson, J., Littlewood-Evans, A., Ludwig, M. G., Seuwen, K., et al. (2017). Design and Synthesis of Potent and Orally Active GPR4 Antagonists with Modulatory Effects on Nociception, Inflammation, and Angiogenesis. Bioorg. Med. Chem. 25 (16), 4512-4525. doi:10.1016/ j.bmc.2017.06.050

Mintenig, G. M., Sánchez-Vives, M. V., Martin, C., Gual, A., and Belmonte, C. (1995). Sensory Receptors in the Anterior Uvea of the Cat's Eye. An In Vitro Study. Invest. Ophthalmol. Vis. Sci. 36, 1615-1624.

Morenilla-Palao, C., Luis, E., Fernández-Peña, C., Quintero, E., Weaver, J. L., Bayliss, D. A., et al. (2014). Ion Channel Profile of TRPM8 Cold Receptors Reveals a Role of TASK-3 Potassium Channels in Thermosensation. Cell Rep. 8 (5), 1571-1582. doi:10.1016/j.celrep.2014.08.003

Moreno-Montañés, J., Bleau, A. M., and Jimenez, A. I. (2018). Tivanisiran, a Novel siRNA for the Treatment of Dry Eye Disease. Expert Opin. Investig. Drugs 27 (4), 421-426. doi:10.1080/13543784.2018.1457647

Murakami, N., Yokomizo, T., Okuno, T., and Shimizu, T. (2004). G2A is a ProtonSensing G-Protein-Coupled Receptor Antagonized by Lysophosphatidylcholine. J. Biol. Chem. 279 (41), 42484-42491. doi:10.1074/ jbc.M406561200

Murata, Y., and Masuko, S. (2006). Peripheral and Central Distribution of TRPV1, Substance P and CGRP of Rat Corneal Neurons. Brain Res. 1085 (1), 87-94. doi:10.1016/j.brainres.2006.02.035

Nakamura, A., Hayakawa, T., Kuwahara, S., Maeda, S., Tanaka, K., Seki, M., et al. (2007). Morphological and Immunohistochemical Characterization of the Trigeminal Ganglion Neurons Innervating the Cornea and Upper Eyelid of the Rat. J. Chem. Neuroanat. 34 (3-4), 95-101. doi:10.1016/ j.jchemneu.2007.05.005

Neira-Zalentein, W., Holopainen, J. M., Tervo, T. M. T., Borrás, F., Acosta, M. C., Belmonte, C., et al. (2011). Corneal Sensitivity in Diabetic Patients Subjected to Retinal Laser Photocoagulation. Invest. Ophthalmol. Vis. Sci. 52 (8), 6043-6049. doi:10.1167/iovs.10-7054

Neubert, J. K., Karai, L., Jun, J. H., Kim, H. S., Olah, Z., and Iadarola, M. J. (2003). Peripherally Induced Resiniferatoxin Analgesia. Pain 104 (1), 219-228. doi:10.1016/s0304-3959(03)00009-5

Nguyen, M. Q., Wu, Y., Bonilla, L. S., von Buchholtz, L. J., and Ryba, N. J. P. (2017). Diversity Amongst Trigeminal Neurons Revealed by High Throughput Single Cell Sequencing. PLoS One 12 (9), e0185543-22. doi:10.1371/ journal.pone. 0185543

Oh, M. H., Oh, S. Y., Lu, J., Lou, H., Myers, A. C., Zhu, Z., et al. (2013). TRPA1Dependent Pruritus in IL-13-Induced Chronic Atopic Dermatitis. J. Immunol. 191 (11), 5371-5382. doi:10.4049/jimmunol.1300300

Okada, Y., Reinach, P. S., Shirai, K., Kitano-Izutani, A., Miyajima, M., Yamanaka, O., et al. (2015). Transient Receptor Potential Channels and Corneal Stromal Inflammation. Cornea 34 (Suppl. 11), S136-S141. doi:10.1097/ ICO.0000000000000602

Olah, Z., Szabo, T., Karai, L., Hough, C., Fields, R. D., Caudle, R. M., et al. (2001). Ligand-induced Dynamic Membrane Changes and Cell Deletion Conferred by Vanilloid Receptor $1^{\star}$. J. Biol. Chem. 276 (14), 11021-11030. doi:10.1074/ jbc.M008392200

Parra, A., Gonzalez-Gonzalez, O., Gallar, J., and Belmonte, C. (2014). Tear Fluid Hyperosmolality Increases Nerve Impulse Activity of Cold Thermoreceptor Endings of the Cornea. Pain 155 (8), 1481-1491. doi:10.1016/j.pain.2014.04.025
Parra, A., Madrid, R., Echevarria, D., del Olmo, S., Morenilla-Palao, C., Acosta, M. C., et al. (2010). Ocular Surface Wetness is Regulated by TRPM8-Dependent Cold Thermoreceptors of the Cornea. Nat. Med. 16 (12), 1396-1399. doi:10.1038/nm.2264

Petersen, M., and LaMotte, R. H. (1993). Effect of Protons on the Inward Current Evoked by Capsaicin in Isolated Dorsal Root Ganglion Cells. Pain 54 (1), 37-42. doi:10.1016/0304-3959(93)90097-9

Pethő, G., and Reeh, P. W. (2012). Sensory and Signaling Mechanisms of Bradykinin, Eicosanoids, Platelet-Activating Factor, and Nitric Oxide in Peripheral Nociceptors. Physiol. Rev. 92 (4), 1699-1775. doi:10.1152/ physrev.00048.2010

Quallo, T., Vastani, N., Horridge, E., Gentry, C., Parra, A., Moss, S., et al. (2015). TRPM8 is a Neuronal Osmosensor that Regulates Eye Blinking in Mice. Nat. Commun. 6, 7150. doi:10.1038/ncomms8150

Reiner, A., Karten, H. J., Gamlin, P. D. R., and Erichsen, J. T. (1983). Parasympathetic Ocular Control - Functional Subdivisions and Circuitry of the Avian Nucleus of Edinger-Westphal. Trends Neurosciences 6, 140-145. doi:10.1016/0166-2236(83)90068-1

Royal, P., Andres-Bilbe, A., Ávalos Prado, P., Verkest, C., Wdziekonski, B., Schaub, S., et al. (2019). Migraine-Associated TRESK Mutations Increase Neuronal Excitability through Alternative Translation Initiation and Inhibition of TREK. Neuron 101 (2), 232-e6. doi:10.1016/j.neuron.2018.11.039

Ruskell, G. L. (1970). The Orbital Branches of the Pterygopalatine Ganglion and Their Relationship with Internal Carotid Nerve Branches in Primates. J. Anat. 106 (Pt 2), 323-339.

Sandoz, G., Douguet, D., Chatelain, F., Lazdunski, M., and Lesage, F. (2009). Extracellular Acidification Exerts Opposite Actions on TREK1 and TREK2 Potassium Channels via a Single Conserved Histidine Residue. Proc. Natl. Acad. Sci. U.S.A. 106 (34), 14628-14633. doi:10.1073/pnas.0906267106

Sano, Y., Inamura, K., Miyake, A., Mochizuki, S., Kitada, C., Yokoi, H., et al. (2003). A Novel Two-Pore Domain K+ Channel, TRESK, is Localized in the Spinal Cord. J. Biol. Chem. 278 (30), 27406-27412. doi:10.1074/ jbc.M206810200

Schecterson, L. C., Pazevic, A. A., Yang, R., Matulef, K., and Gordon, S. E. (2020). TRPV1, TRPA1, and TRPM8 are Expressed in Axon Terminals in the Cornea: TRPV1 Axons Contain CGRP and Secretogranin II; TRPA1 Axons Contain Secretogranin 3. Mol. Vis. 26, 576-587.

Schuhmacher, L. N., and Smith, E. S. (2016). Expression of Acid-Sensing Ion Channels and Selection of Reference Genes in Mouse and Naked Mole Rat. Mol. Brain 9 (1), 97. doi:10.1186/s13041-016-0279-2

Singh, P., Tyagi, M., Kumar, Y., Gupta, K. K., and Sharma, P. D. (2013). Ocular Chemical Injuries and Their Management. Oman J. Ophthalmol. 6 (2), 83-86. doi:10.4103/0974-620X.116624

Staikopoulos, V., Sessle, B. J., Furness, J. B., and Jennings, E. A. (2007). Localization of P2X2 and P2X3 Receptors in Rat Trigeminal Ganglion Neurons. Neuroscience 144 (1), 208-216. doi:10.1016/j.neuroscience.2006.09.035

Szolcsányi, J., and Sándor, Z. (2012). Multisteric TRPV1 Nocisensor: a Target for Analgesics. Trends Pharmacol. Sci. 33 (12), 646-655. doi:10.1016/j.tips.2012.09.002

ten Tusscher, M. P., Beckers, H. J., Vrensen, G. F., and Klooster, J. (1994). Peripheral Neural Circuits Regulating IOP? A Review of its Anatomical Backbone. Doc. Ophthalmol. 87 (4), 291-313. doi:10.1007/BF01203340

Thygesen, J. (2018). Glaucoma Therapy: Preservative-free for All? Clin. Ophthalmol. 12, 707-717. doi:10.2147/OPTH.S150816

Tominaga, M., Caterina, M. J., Malmberg, A. B., Rosen, T. A., Gilbert, H., Skinner, K., et al. (1998). The Cloned Capsaicin Receptor Integrates Multiple Pain-Producing Stimuli. Neuron 21 (3), 531-543. doi:10.1016/s0896-6273(00)80564-4

Tóth, A., Boczán, J., Kedei, N., Lizanecz, E., Bagi, Z., Papp, Z., et al. (2005). Expression and Distribution of Vanilloid Receptor 1 (TRPV1) in the Adult Rat Brain. Brain Res. Mol. Brain Res. 135 (1-2), 162-168. doi:10.1016/ j.molbrainres.2004.12.003

Usoskin, D., Furlan, A., Islam, S., Abdo, H., Lönnerberg, P., Lou, D., et al. (2015). Unbiased Classification of Sensory Neuron Types by Large-Scale Single-Cell RNA Sequencing. Nat. Neurosci. 18 (1), 145-153. doi:10.1038/nn.3881

Vullo, S., and Kellenberger, S. (2019). A Molecular View of the Function and Pharmacology of Acid-Sensing Ion Channels. Pharmacol. Res. 154, 104166. doi:10.1016/j.phrs.2019.02.005

Walder, R. Y., Rasmussen, L. A., Rainier, J. D., Light, A. R., Wemmie, J. A., and Sluka, K. A. (2010). ASIC1 and ASIC3 Play Different Roles in the Development 
of Hyperalgesia After Inflammatory Muscle Injury. J. Pain 11 (3), 210. doi:10.1016/j.jpain.2009.07.004

Waldmann, R., Champigny, G., Bassilana, F., Heurteaux, C., and Lazdunski, M. (1997). A Proton-Gated Cation Channel Involved in Acid-Sensing. Nature 386 (6621), 173-177. doi:10.1038/386173a0

Wang, J. Q., Kon, J., Mogi, C., Tobo, M., Damirin, A., Sato, K., et al. (2004). TDAG8 is a Proton-Sensing and Psychosine-Sensitive G-Protein-Coupled Receptor. J. Biol. Chem. 279 (44), 45626-45633. doi:10.1074/jbc.M406966200

Wemmie, J. A., Taugher, R. J., and Kreple, C. J. (2013). Acid-sensing Ion Channels in Pain and Disease. Nat. Rev. Neurosci. 14 (7), 461-471. doi:10.1038/nrn3529

Weyer-Menkhoff, I., and Lötsch, J. (2018). Human Pharmacological Approaches to TRP-Ion-Channel-Based Analgesic Drug Development. Drug Discov. Today 23 (12), 2003-2012. doi:10.1016/j.drudis.2018.06.020

Wilson, S. R., Nelson, A. M., Batia, L., Morita, T., Estandian, D., Owens, D. M., et al. (2013). The Ion Channel TRPA1 Is Required for Chronic Itch. J. Neurosci. 33 (22), 9283-9294. doi:10.1523/JNEUROSCI.5318-12.2013

Yamamoto, Y., Hatakeyama, T., and Taniguchi, K. (2009). Immunohistochemical Colocalization of TREK-1, TREK-2 and TRAAK with TRP Channels in the Trigeminal Ganglion Cells. Neurosci. Lett. 454 (2), 129-133. doi:10.1016/ j.neulet.2009.02.069

Yang, Y., Yang, H., Wang, Z., Okada, Y., Saika, S., and Reinach, P. S. (2013a). Wakayama Symposium: Dependence of Corneal Epithelial Homeostasis on Transient Receptor Potential Function. Ocul. Surf. 11 (1), 8-11. doi:10.1016/ j.jtos.2012.09.001

Yang, Y., Yang, H., Wang, Z., Varadaraj, K., Kumari, S. S., Mergler, S., et al. (2013b). Cannabinoid Receptor 1 Suppresses Transient Receptor Potential Vanilloid 1-Induced Inflammatory Responses to Corneal Injury. Cell Signal 25 (2), 501-511. doi:10.1016/j.cellsig.2012.10.015
Zeisel, A., Hochgerner, H., Lönnerberg, P., Johnsson, A., Memic, F., van der Zwan, J., et al. (2018). Molecular Architecture of the Mouse Nervous System. Cell 174 (4), 999-1014.e22. doi:10.1016/j.cell.2018.06.021

Zhang, F., Yang, H., Wang, Z., Mergler, S., Liu, H., Kawakita, T., et al. (2007). Transient Receptor Potential Vanilloid 1 Activation Induces Inflammatory Cytokine Release in Corneal Epithelium through MAPK Signaling. J. Cell Physiol. 213 (3), 730-739. doi:10.1002/jcp.21141

Zhang, X., Vadoothker, S., Munir, W. M., and Saeedi, O. (2019). Ocular Surface Disease and Glaucoma Medications: A Clinical Approach. Eye Contact Lens 45 (1), 11-18. doi:10.1097/ICL.0000000000000544

Conflict of Interest: The authors declare that the research was conducted in the absence of any commercial or financial relationships that could be construed as a potential conflict of interest.

Publisher's Note: All claims expressed in this article are solely those of the authors and do not necessarily represent those of their affiliated organizations, or those of the publisher, the editors and the reviewers. Any product that may be evaluated in this article, or claim that may be made by its manufacturer, is not guaranteed or endorsed by the publisher.

Copyright (c) 2021 Comes, Gasull and Callejo. This is an open-access article distributed under the terms of the Creative Commons Attribution License (CC $B Y$ ). The use, distribution or reproduction in other forums is permitted, provided the original author(s) and the copyright owner(s) are credited and that the original publication in this journal is cited, in accordance with accepted academic practice. No use, distribution or reproduction is permitted which does not comply with these terms. 